\section{A. ARS BILDUMA ISSN 1989-9262 UPV/EHU Press} ARSBILDUMA (CC BY-NC-ND 4.0)

https://doi.org/10.1387/ars-bilduma.22521 BIBLID [(2021), 11; 171-193]

Recibido: 17/12//2020 Aceptado: 12/01/2020

\section{CARLOS POLANCO MELERO}

Universidad de Burgos

Facultad de Humanidades y Comunicación Paseo de los Comendadores, $\mathrm{s} / \mathrm{n}$

09001 Burgos (Burgos)

mcarlos@ubu.es

https://orcid.org/0000-0003-4577-0554

\title{
UN DESTELLO ARQUITECTÓNICO DEL SIGLO XIV: LA CA- PILLA DE SANTA CATALINA, ANTIGUA SALA CAPITULAR DE LA CATEDRAL DE BURGOS
}

\section{A $14^{\text {TH }}$ CENTURY ARCHITECTURAL SPARKLE: THE CHAPEL OF SANTA CATALINA, THE FORMER CHAPTER HOUSE OF BURGOS CATHEDRAL}

UNE LUEUR ARCHITECTURALE DU XIVE SIECLE: LA CHAPELLE DE SAINTE CATHERINE, ANCIENNE SALLE CAPITULAIRE DE LA CATHÉDRALE DE BURGOS

RESUMEN

La Capilla de Santa Catalina de la Catedral de Burgos presenta un novedoso abovedamiento, análogo al de la Capilla Barbazana de la Catedral de Pamplona. El edificio burgalés pudo preceder al pamplonés y se aportan elementos argumentales en este sentido. Las capillas funerarias de la segunda mitad del siglo XIV y del tardogótico castellano entroncan con su configuración espacial y arquitectónica. En la arquitectura religiosa, su impronta se extiende hasta finales del siglo XV.

\section{PALABRAS CLAVE}

Capilla de Santa Catalina; Capilla Barbazana; sala capitular; bóveda ochavada; bóveda estrellada; siglo XIV.
ABSTRACT

The Chapel of Santa Catalina in Burgos Cathedral presents a similar vaulting to that of the Barbazana Chapel in Pamplona Cathedral. The work in Burgos may have preceded the one in Pamplona, and thi article provides some evidence in this regard. Funerary chapels of the second half of the $14^{\text {th }}$ century and the late Gothic period in Castile relate to its new spatial and architectural configuration. In religious architecture, their imprint extends to the end of the 15th century.

\section{KEYWORDS}

Santa Catalina Chapel; Barbazana Chapel; chapter house; octagonal vault; star-shaped vault; 14 th century.
RÉSUMÉ

La Chapelle de Sainte Catherine de la Cathédrale de Burgos présente un voûtement novateur, similaire à celui de la Chapelle Barbazana de la Cathédrale de Pampelune. Cette ouvre de Burgos pourrait avoir précédé celle de Pampelune et on apporte des arguments dans ce sens. Les chapelles funéraires de la deuxième moitié du XIV ${ }^{e}$ siècle et du gothique tardif castillan rejoignent leur nouvelle configuration spatiale et architecturale. Dans l'architecture religieuse, on en voit les traces jusqu’à la fin du XVè siècle.

\section{MOTS-CLÉS}

Chapelle de Santa Catalina; Chapelle Barbazana; salle capitulaire; voûte octogonale; voûte en forme détoile; $14 \mathrm{e}$ siècle. 


\section{FUNDACIÓN DE LA CAPILLA DE SANTA CATALINA}

La información más relevante que proporciona el Archivo de la Catedral de Burgos sobre la Capilla de Santa Catalina la dieron a conocer don Manuel Martínez Sanz $z^{1}$ y don Teófilo López Mata $^{2}$. El primero de ellos transcribió lo esencial del documento fundacional del edificio, promovido por el obispo don Gonzalo de Hinojosa y fechado el 13 de septiembre de $1316^{3}$.

A finales del siglo XIII la sala capitular de la Catedral de Burgos estaba emplazada en el claustro de la catedral románica o claustra vieja. En 1291 se identifica por primera vez el lugar de reunión del Cabildo con la Capilla de San Pablo ${ }^{4}$. Del documento fundacional de la Capilla de Santa Catalina se deduce que a juicio de los canónigos este espacio no reunía las condiciones requeridas para desempeñar adecuadamente esta función. La iniciativa del obispo está motivada, en primer término, por esta circunstancia, de modo que vincula su decisión a los "muchos embargos que el Dean e el Cabildo de nuestra eglesia reciben a las vegadas en la cappiella de Sant Paulo do suelen facer Cabildo". Las incomodidades se evidenciaban asimismo con ocasión de las visitas reales, lo que se explica por la proximidad del palacio episcopal, donde se aposentaban. La puerta de acceso al palacio desde la claustra vieja estaba junto a la Capilla de San Pablo ${ }^{5}$, hecho que, sin duda, favorecía el trasiego de personas de la corte y del servicio real.

Hay factores que la documentación no puede explicitar. Es frecuente que los deseos, más o menos fundados en la necesidad, se sustancien en la exposición de los inconvenientes y perjuicios que produce aquello que se pretende modificar o sustituir. En este caso, no reflejan

1 MARTÍNEZ SANZ, M.: Historia del Templo Catedral de Burgos escrita con arreglo a documentos de su Archivo, Imprenta de Don Anselmo Revilla, Burgos, 1866, pp. 138-143 y 296-298. Utilizo la edición facsímil con estudio, bibliografía e índices de IBÃNEEZ PÉREZ, A.C. y BALLESTEROS CABALLERO, F., Asociación Amigos de la Catedral-Fundación para el apoyo de la Cultura, Burgos, 1997.

2 LÓPEZ MATA, T.: La Catedral de Burgos. Hijos de Santiago Rodríguez, Burgos, 1966, pp. 383-387. Reedición con estudio introductorio de MATASANZ DEL BARRIO, J., Instituto Municipal de Cultura y Turismo, Ayuntamiento de Burgos, Burgos, 2008

3 Archivo de la Catedral de Burgos (ACB). V. 41 1. Fol. 417- Burgos, 13/09/1316. MARTíNEZ SANZ, M. op. cit., pp. 296-297. PEREDA LLANERA, F. J.: Documentación de la Catedral de Burgos (1294-1316). Garrido Ediciones, Burgos, 1984, doc. 500, pp. 381-383

4 MARTÍNEZ SANZ, M.: op. cit., p. 149.

5 La sepultura de los padres del racionero Juan Bonifaz de la Riva estaba situada en la procesión vieja delante de la Capilla de San Pablo, por donde el obispo entra a los palacios. Archivo de la Catedral de Burgos (ACB). RR-4, 166v-169. 30/10/1424. sino la voluntad de los canónigos de engrandecer la dependencia más representativa de su personalidad como institución diferenciada de la autoridad episcopal e integrarla en el complejo catedralicio renovado, ocupando un espacio relevante en el mismo. El cambio de emplazamiento permitió dejar atrás los vestigios empequeñecidos de la catedral románica $y$, ante todo, reafirmar la autonomía del Cabildo frente al obispo, mediante un evidente distanciamiento espacial de la sala capitular respecto al palacio episcopal, en el cual, al cabo, se integró la Capilla de San Pablo. La identificación de la Capilla de San Pablo con el palacio episcopal progresa con el tiempo: pasa de estar junto a los palacios episcopales en $1435^{6}$ a que estos se amplíen a su costa (en 1523 el provisor del obispado declara que el palacio episcopal estaba edificado sobre dos pandas del claustro viejo ${ }^{7}$ ) hasta, finalmente, formar parte de los mismos cuando, avanzado ya el siglo XVI, se habla de la "Capilla de la Conversión de San Pablo del palacio episcopal"'.

Se trata de un episodio que se inscribe en el proceso histórico de emancipación del Cabildo, que se había iniciado a mediados del siglo XII con su secularización y el consiguiente abandono de la vida regular en torno al claustro viejo y el palacio episcopal'. Después de que el esfuerzo financiero y artístico durante el siglo XIII se hubiera concentrado en la construcción de un magnífico templo y de un claustro que lo complementase, era el momento de incorporar una nueva sala capitular al complejo catedralicio. Quien dio satisfacción a esta aspiración fue el obispo don Gonzalo de Hinojosa, promovido a la sede de Burgos en 1313, después de haber ocupado la silla episcopal de León desde $1301^{10}$, para sustituir a don Pedro Rodríguez de Quijada, fallecido ese mismo año en Aviñón. La condición de fraile benedictino del obispo, probablemente del monasterio de San Pedro de Arlanza ${ }^{11}$, pudo influir en la decisión de dotar al capítulo catedralicio de un renovado espacio de reunión, dependencia de primer orden en la vida monástica.

6 ACB. RR-8, 261v, 29/03/1435.

ACB. Lib-46, 379-382. 02/1523

8 ACB. RR-59, 29/03/1578. RR-64, 98v. 12/06/1579. La Capilla de San Pablo fue derribada en 1859 (CORTÉS ECHANOVE, L.: "De cómo la ciudad de Burgos logró el aislamiento de su Catedral", Boletín de la Institución Fernán González, n. ${ }^{\circ} 176,1971$, pp. 522-557).

9 PEÑA PÉREZ, F. J.: "El Alma del Templo. El Cabildo catedralicio", en PAYO HERNANZ, R. J. (coord.): La Catedral de Burgos. Ocho siglos de historia y arte, Diario de Burgos-Promecal, Burgos, 2008, pp. 125-143.

10 ORDÁS DÍAZ, P.: “¿Don Gonzalo Osorio de Villalobos o don Gonzalo de Hinojosa? Un episcopado olvidado en León, 1301-1313", e-Spania "(consultado el 1/05/2020). https://doi.org/10.4000/e-spania.26454.

1 MARTÍNEZ AÑíBARRO Y RIVES, M.: Intento de un Diccionario Biográfico y Bibliográfico de au- 
Otra motivación traída a colación por el obispo para justificar la construcción de la nueva dependencia claustral fue su uso "para enterramientos que son mucho mester", aunque no existiera verdadera necesidad de ello porque, en 1316, los canónigos disponían de diferentes espacios funerarios. En primer lugar, la claustra vieja, cuyo uso funerario estaba plenamente vigente en los primeros años del siglo XIV, cuando se abren numerosos arcosolios sepulcrales con inscripciones, aún hoy visibles en las pandas sur y oeste ${ }^{12}$. Por otra parte, estaban las capillas perimetrales de la catedral de Burgos, ligadas a usos funerarios desde $1230^{13}$, cuyo número se acrecienta a principios del siglo XIV con las capillas de Santa Ana y San Bartolomé, fundada en 1308, y la de San Antolín, que debió hacerse inmediatamente después de aquella ${ }^{14}$, abiertas a la nave norte, y la capilla de Santa Catalina, en la nave sur, mencionada por primera vez en $1309^{15}$. Asimismo, el claustro nuevo estaba dotado de paramentos retranqueados en arcosolios monumentales destinados a albergar sepulcros en las pandas este, sur y oeste ${ }^{16}$. Tal repertorio de espacios sepulcrales condujo a que la función funeraria de la nueva sala capitular catedralicia, habitual en el ámbito monástico del que procedía el obispo, no llegara a materializarse nunca ${ }^{17}$.

La cuarta y última razón que aduce don Gonzalo de Hinojosa es el perjuicio que causaba al claustro una casa adosada por la parte de La Llana, probablemente porque, al ser de mayor altura, vertía aguas sobre la panda oriental. El solar de estas casas, "en que moraba maestre Arnal Abbat de Franuncea", era donde, principalmente, se habría de edificar la capilla, junto con "otra parte de casas en que sole otrossi morar el dicho Abbat de Franuncea que es

tores de la provincia de Burgos. Madrid, imprenta y fundición de Manuel Tello, 1889, p. 197. ZARA GOZA PASCUAL, E.: "Hinojosa (o Finojosa), Gonzalo", DB-e, Diccionario Biográfico Español de la Real Academia de la Historia. http://dbe.rah.es/biografias/50606/gonzalo-de-hinojosa (consultado el 22/03/2019)

12 ABELLA VILLAR, P.: "El complejo catedralicio burgalés a lo largo de la Edad Media (siglos XI-XIV). Hipótesis para un debate", Porticvm. Revista d'Estudis Medievals, n. ${ }^{\circ}$ III, 2012, pp. 7-34.

13 BANGO TORVISO, I.: "El espacio para enterramientos privilegiados en la arquitectura medieval española", Anuario del Departamento de Historia y Teoría del Arte. (U.A.M.). Vol. IV, 1992, pp. 93-312.

14 KARGE, H.: La Catedral de Burgos y la Arquitectura del siglo XIII en Francia y España. Junta de Castilla y León, Consejería de Cultura y Turismo, Valladolid, 1995, p. 58.

15 LÓPEZ MATA, T.: op. cit., p. 265

16 CARRERO SANTAMARÍA, E. "El claustro funerario en el medievo o los requisitos de una arquitectura de uso cementerial", Liño 12. Revista Anual de Historia del Arte, 2006, pp. 31-44.

17 Tampoco sirvió para enterramiento del obispo Hinojosa, fallecido en 1327, cuyo cuerpo fue sepultado en la Capilla de San Juan Apóstol y Evangelista (hoy conocida como de San Gregorio), donde se emplazó el sepulcro mural que aún se conserva. prestimonial". Estas casas eran contiguas a otras "en que mora maestre Ricardo, canónigo de nuestra eglesia, que las ha en préstamo". Este canónigo, en el momento de hacerse la escritura, ocupaba también las casas citadas anteriormente como vivienda del Abad de Franuncea. El propietario de sendos inmuebles era el Cabildo, quien da "las casas y parte de casas" para "facer Cabildo e cal por do puedan pasar del barrio de parte de La Llana a la cal que va a mercado ${ }^{18}$ ", comprometiéndose el obispo a pagar a la mesa capitular 450 maravedíes por juro de heredad.

La nueva dependencia se erigió en terrenos propiedad del Cabildo, pero a costa de las rentas episcopales. Por este motivo el prelado declara su intención de procurar que la fundación se haga "sin nuestro perjuicio en todo", preservando la preeminencia de la autoridad episcopal sobre la capilla, que se concreta en la capacidad de que los capitulares "fagan Cabillo en S. Paulo cuando nos mandáremos o nuestros sucessores", circunstancia que no debió ejecutarse sino excepcionalmente y en fechas relativamente tempranas. Asi, consta una reunión capitular en la Capilla de San Pablo en $1408^{19}$ y otra en la Capilla de San Juan Bautista en $1419^{20}$. El ascendiente episcopal sobre el edificio capitular se manifestó plásticamente en el remate de la fachada que mira al claustro, coronada con la imagen exenta de un obispo.

La nueva sala capitular se pensó varias décadas después de que el claustro gótico estuviera finalizado en su totalidad, según la cronología propuesta por Karge $(1265-1270)^{21}$. La elección del emplazamiento en la panda oriental responde a la tradicional ubicación de

18 La obra de la Capilla de Santa Catalina tuvo cierta repercusión en la trama urbana próxima al claustro catedralicio, pues su proyecto no contemplaba usar ha totalidad de la superficie liberada por eldertibo ás edificios adosados a la panda oriental del chautro existir no tuvieron la misma anchura o profundidad que los citados en la escritura, lo que permitió que el derribo de estos últimos dejara abierto un paso entre La Llana y la calle que iba al Mercado, actua calle Diego Porcelos. La calle resultante debió ser muy estrecha. En 1643, se reparó el vuelo del tejado de la Capilla de Santa Catalina "que cae a las casas de Rodrigo de Castro" (MATESANZ DEL BARRIO, J.: Actividad artística en la Catedral de Burgos de 1600 a 1765. Excma. Diputación Provincial de Burgos, Burgos, 2001, p. 295). En 1895 el Ayuntamiento autorizó el derribo de tres casas en la Llana de Afuer $y$ ensanchol, p. 295). En 1895 el Ay nueva alineación.

19 ACB. LIB-63, 754v, 10/01/1408.

20 ACB. RR-9, 215. 15/09/1419.

21 KARGE, H.: op. cit., p. 109. 
esta dependencia en monasterios y catedrales, pero en la Catedral de Burgos era, además, la única que ofrecía esta posibilidad. El ala occidental lindaba con el acceso a la puerta del Sarmental y el meridional estaba limitado por una esgueva y vía pública (la que será calle de la Cerrajería), obstáculo insalvable por la celosa protección que el Concejo ejercía sobre los terrenos de la ciudad, como reflejan las fricciones habidas con el Cabildo en $1295^{22}$. Por otra parte, la presencia en claustros catedralicios hispanos bajomedievales de edificaciones únicamente en el lado oriental (Lérida, Huesca, Santiago de Compostela) se ha relacionado con la reducción del número de dependencias necesarias como consecuencia de la secularización de los cabildos ${ }^{23}$

\section{APROVECHAMIENTO DE LA PANDA ORIENTAL DEL CLAUSTRO}

La nueva sala capitular era el primer edificio que se erigía adosado al claustro, pero no pudo ubicarse en el centro geométrico de la panda oriental porque esta está compuesta de ocho tramos, de modo que el acceso se emplazó en el cuarto tramo desde el norte, el más próximo al punto medio de la panda y, a la vez, del templo catedralicio. El edificio tiene planta cuadrada, pero su única portada -en cuyo tímpano se representa en relieve el Descendimiento de la Cruz- no se encuentra tampoco en el centro de su lado occidental, sino ligeramente desplazada hacia el ángulo suroeste; por el contrario, la ventana del muro testero sí que está centrada. Estos detalles indican que el emplazamiento de la capilla responde a las características concretas del solar donde se edificó y que este, muy probablemente, estuvo inicialmente limitado por otras construcciones.

Con la fundación de la Capilla de Santa Catalina, el obispo Hinojosa inició el aprovechamiento arquitectónico del ámbito claustral, centrado en la panda oriental. En el lado sur de la sala capitular se construyó una capilla denominada de Juan Estébanez en $1375^{24}$. Los rasgos estilísticos del sepulcro de un caballero que está en medio, hacia la parte del altar, sitúan su cronología a finales del siglo XIV ${ }^{25}$. En 1415 se la menciona

22 LÓPEZ MATA, T.: op. cit., pp. 365-366

23 ABELLA VILAR, P.: op, cit., p. 32, nota 149

24 MARTÍNEZ SANZ, M.: op. cit., p. 146. LÓPEZ MATA, T.: op. cit., p. 390

25 GÓMEZ BARCENA, M. J.: Escultura gótica funeraria en Burgos. Excma. Diputación Provincial de Burgos, Burgos, 1988, p. 83 por vez primera como Capilla del Cuerpo de $\operatorname{Dios}^{26}$, denominación que es predominante desde entonces ${ }^{27}$. La temprana vinculación de la capilla a la nobleza, así como la presencia de figuras de donantes en la portada, parecen fundamentar, en ausencia de testimonios documentales, la idea de que se trata de la primera capilla vinculada a un comitente civil, iniciando una nueva forma de promoción artística que en la Catedral de Burgos alcanzará su apogeo en el siglo $\mathrm{XV}^{28}$. Cosa distinta es que se haya identificado correctamente al promotor de la capilla, porque en el siglo XIV se suceden dos personajes homónimos. El primero es merino de la ciudad de Burgos en 1335 y posteriormente canciller de Alfonso XI. Cayó en desgracia en 1351, con Pedro I, y falleció en 1352 combatiéndole ${ }^{29}$. Si este fuera

26 MARTÍNEZ SANZ, M.: op cit., p. 300

27 LÓPEZ MATA, T.: op. cit., p. 391

28 PAYO HERNANZ, R. J.: "La Catedral de Burgos. Un universo de formas a través de ocho siglos de historia", PAYO HERNANZ, R. J. (coord.): La Catedral de Burgos, Ocho siglos de historia y arte, Diario de Burgos-Promecal, Burgos, 2008, pp. 81-118.

29 Martínez Sanz habla del Juan Estébanez de Burgos que cita Lope de Ayala en su Crónica del rey don Pedro y del rey don Enrique su hermano (op. cit., pp. 298-299). Fue escribano de Alfonso XI desde 133 y llegó a ser nombrado canciller por el rey en 1344 (GONZÁLEZ CRESPO, E.: "Organización de la cancillería castellana en la primera mitad del siglo XIV”, La España Medieval, n. ${ }^{\circ} 8$, 1986, pp. 447-470). Era vecino de Sahagún donde tenía su casa solariega, pero estuvo asimismo vinculado a la ciudad Burgos, donde en 1335 aparece como merino del rey (ACB. V 40, 212. Burgos, 17/11/1335), y a su tierra, porque dispuso de derechos señoriales en cuatro lugares del entorno burgalés, tres de la zona de Juarros (Cueva, Espinosa e Ibeas), con derechos solariegos, y en Belbimbre, de la merindad de Burgos, que era de realengo pero, según el Becerro de las Behetrías, lo "solía tener" por merced del monarca (ÁLVAREZ BORGE, I.: "Nobleza y señoríos en Castilla la Vieja meridional a mediados del siglo XIV", Brocar. Cuadernos de Investigación Histórica, n. ${ }^{\circ}$ 1, 1998, pp. 55-117). López Mata recoge noticias de su caída en desgracia, tras la muerte de Alfonso XI a cuyo servicio había prosperado (op. cit., pp. 390-391). En 1350 participó en la lucha de facciones nobiliarias, siendo aún Pedro I menor edad y, con motivo de la enfermedad que amenazó la vida del rey se inclinó por la candidatura de Juan Núñez de Lara, señor de Vizcaya. En 1351, al dirigirse Pedro I hacia Burgos, Jan Estóba caído ya en desgracia, aba la ciudad para refugiarse en Aragón. Pedro I le declara traidor y confisca sus bienes, entregando los que tenía en Sahagún al monasterio de esa villa (DÍAZ MARTÍN, L. V.: Los orígenes de la Audiencia Rea castellana, Secretariado de Publicaciones de la Universidad de Sevilla, 1997, pp. 69-70). En Aragón fue apresado por Pedro IV a petición del monarca castellano, pero logró escapar de Daroca, donde estaba retenido, y reunirse con Alfonso Fernández Coronel en Aguilar de la Frontera (Córdoba), último reducto de la nobleza rebelde. Allí murió en 1352, durante el cerco de la villa. Este es un personaje cuya biografía ha sido de objeto de algunos estudios biográficos como MOXÓ ORTIZ, S.: "Juan Estévanez de Castellanos. Flevación y caíla de un conejero regio en a Custlla del siglo XIV", Studia Silensia. Tame Santo Domingo de Silos, Burgos, 1976, pp. 407-422; VALDALISO CASANOVA, C.: "Estévanez de Castellanos, Juan”, Diccionario Biográfico Español (DB-e), Real Academia de la Historia. http://dbe.rah.es/ biografias/60265/juan-estevanez-de-castellanos (consultado el 14/04/2019). GLERO DE LA FUENTE 
el promotor de la Capilla del Corpus Christi, como presuponen algunos autores ${ }^{30}$, esta obra sería prácticamente coetánea de la Capilla de Santa Catalina. La ausencia de noticias en fechas tan tempranas y, sobre todo, en relación con la construcción de la sala capitular, nos inclina a identificar como promotor a Juan Estébanez de Castellanos, merino mayor de Castilla en 1371, personaje peor conocido y que López Mata confunde con el anterior, error que generalmente aún se mantiene. Éste fue quien en febrero de 1379 vendió la hacienda que poseía en Cabia a Juan Martínez de Rojass ${ }^{31}$, señor de Monzón y de Cabia ${ }^{32}$, fallecido en 1384 en el sitio de Lisboa, cuya viuda, doña María de Rojas, sería promotora de la segunda capilla de patronazgo nobiliario de la Catedral de Burgos, la Capilla de Santa Catalina de los Rojas, a finales del siglo XIV ${ }^{33}$. La prosperidad de este segundo Juan Estébanez de Castellanos, que responde a las mercedes recibidas de Enrique II por el apoyo que le había prestado en la guerra con Pedro I, le permitirán materializar su ascenso social en la construcción de una capilla propia. Este edificio habría sido construido entre 1371, siendo merino mayor de Castilla, y 1375, cuando se tiene la primera noticia de su existencia. Breve espacio de tiempo que está en concordancia con su modesta arquitectura, sobre todo si se compara con la grandiosidad de la inmediata sala capitular. Un parentesco directo entre ambos personajes homónimos es muy probable, máxime cuando vemos al segundo de ellos comprometido con el bando del conde de Trastámara, enfrentado a Pedro I, monarca causante de la ruina y muerte del primero.

Después de que se terminara la Capilla de Juan Estébanez, se erigió, en el lado norte de la sala capitular, a finales del siglo XIV o principios del XV, la Capilla de San Juan Bautista, probablemente por iniciativa capitular pero pronto utilizada como lugar de enterramiento por la familia Cabeza de Vaca ${ }^{34}$. Las estatuas yacentes de Pedro Fernández Cabeza de Vaca, C.M.: "Juan Estébanez de Castellanos, canciller de Alfonso XI: entre Sahagún y Burgos", en DEL VAL en la Edad Media. Homenaje al profesor Juan Antonio Bonachía Hernando, Universidad de Valladolid, Valladolid, 2019, pp. 53-62

30 GOMEZ BARCENA, M. J.: op. cit., p. 84. ABEGG, R.: Königs- und Bischof Monumente. Die Skulpturen des 13. Jahrhunderts im Kreuzgang der Kathedrales von Burgos. Zurich InterPublishers, Zurich, 1999, p. 25.

31 Archivo Histórico de la Nobleza. POZA, CP. 329, D. 8. Cabia, 24/02/1379. Escritura otorgada por Juan Estébanez de Castellanos por la que vende a Juan Martínez de Rojas la hacienda que posee en Cabia.

32 LÓPEZ MATA, T.: op. cit., p. 267

33 Ibid., p. 266.

34 Según López Mata la Capilla de San Juan Bautista se construyó a finales del siglo XIV. Él mismo proporciona el primer testimonio escrito de su existencia, de 1411 (MATA LÓPEZ, T.: op. cit., p. 307).
Maestre de la Orden de Santiago, fallecido en 1384 en el sitio de Lisboa, y de su hermano Juan Cabeza de Vaca, obispo de Burgos desde 1406 hasta su fallecimiento en 1412, reubicadas en el siglo XVI en sendos sepulcros murales, presentan rasgos estilísticos de susodicha cronología ${ }^{35}$. Esta primera capilla de San Juan Bautista fue de menor altura que la sala capitular contigua, alcanzando el primer cuerpo de esta, hasta la moldura sobre la que se abre su ventanal apuntado. De ello queda constancia en el exterior, donde se aprecia el perfil de la parte superior del contrafuerte noreste de la Capilla de Santa Catalina como una línea vertical de discontinuidad con el paramento de la reconstrucción de la Capilla de San Juan que el maestro de cantería Juan de Vallejo dirigió en el siglo XVI.

Tanto la Capilla de Juan Estébanez como la de San Juan Bautista se edificaron alineadas a la de Santa Catalina, que se toma como referencia del ordenamiento espacial y arquitectónico de la panda. Con estas adiciones arquitectónicas el claustro adquirió nuevas funcionalidades que se sumaron a las funciones funeraria y procesional primigenias.

\section{CRONOLOGía de la CAPIlla de SANTA CATAlina}

No existe constatación documental del inicio ni de la finalización de la nueva sala capitular. Se viene considerando el año 1316 como el de inicio de la edificación por ser cuando fue promovida por don Gonzalo de Hinojosa. No obstante, parece evidente que a mediados de 1325 no se habían comenzado las obras porque el 1 de julio don Gonzalo de Hinojosa instaba al provisor de los bienes de la obra de la iglesia el derribo de las casas en que vivía el canónigo Ricardo ${ }^{36}$ y que se le procurase una nueva casa a costa de la mesa capitular ${ }^{37}$. Se deduce, por tanto, que el suelo destinado a la capilla no estaba despejado. La reiteración en las palabras del obispo del carácter novedoso e inmediato de su mandato ("por razon de la obra nueva que mandamos agora facer cerca de la nuestra Eglesia de parte de la llana para el Cabildo" ${ }^{38}$ ) parecen indicar que está relanzando la iniciativa fundacional de septiembre de 1316. De ser así, el proyecto arquitectónico original estuvo paralizado durante casi nueve años, periodo en el que se podrían haber introducido modificaciones.
35 GÓMEZ BÁRCENA, M. J.: op. cit., pp. 81-82.

6 MARTÍNEZ SANZ, M.: op. cit., p. 298

37 ACB. V-18, 105. Quintanadueñas, 1/07/1325.

38 MARTÍNEZ SANZ, M.: op. cit., p. 298 
Respecto a la conclusión de las obras podemos tomar como referencia el día 1 de mayo de 1354, cuando se tiene constancia escrita de una primera reunión del Cabildo en la Capilla de Santa Catalina, dato que dio a conocer Martínez Sanz ${ }^{39}$, quien identifica "el Cabildo nuevo que es en la claustra nueva" con la dependencia promovida por don Gonzalo de Hinojosa. Este autor afirma que la sala capitular se siguió llamando "cabildo nuevo" hasta 1374, cuando, en un documento de 25 de agosto, se suma a la anterior denominación la advocación de Santa Catalina ${ }^{40}$. Las objeciones que planteó López Mata respecto a identificar "Cabildo nuevo" y "Capilla de Santa Catalina" antes de 1374 no parecen hoy estar suficientemente fundadas ${ }^{41}$. La documentación catedralicia ofrece noticias suficientes que disipan definitivamente cualquier duda al respecto. En primer lugar, la Capilla de Santa Catalina se cita en 1369 con motivo de la fundación de dos capellanías ${ }^{42}$ y la realización del inventario de sus ornamentos ${ }^{43}$. Por otra parte, en un documento de 15 de diciembre de 1369 que recoge la reducción de las capellanías de la Catedral por parte del obispo don Domingo de Arroyuelo, se mencionan nuevamente las capellanías de la Capilla de Santa Catalina ${ }^{44}$. Todo ello supone la existencia de un altar donde celebrar misas lo cual, a su vez, indica que la capilla estaba terminada, al menos, en 1369. Asimismo, el 13 de abril de 1370 Enrique II dotó con 30.000 maravedíes las capellanías que, desde entonces, se llamarán de los Reyes ${ }^{45}$, dotación que diez años después confirmó su padre, Juan $\mathrm{I}^{46}$. La existencia de un altar y dos capellanías en 1369 y la donación real de 1370 indican que la capilla estaba en pleno uso en esos años, y, por consiguiente, es más fácil aceptar el acierto de Martínez Sanz al identificar "Cabildo nuevo" y Capilla de Santa Catalina desde 1354. En conclusión, una datación plausible y fundada de la edificación de la Capilla de Santa Catalina podría tener como términos cronológicos los días 1 de julio de 1325, cuando se ordena el derribo de las casas en las que vivía Maestre Ricardo, y 1 de mayo de 1354, primera noticia escrita de una reunión del Cabildo en la nueva sala capitular.

$39 I b i d .$, p. 141. La última reunión capitular en la Capilla de San Pablo se registró el 16 de febrero de ese año (id., p. 149)

40 "Cabildo nuevo en la capilla de Santa Catalina en la claustra nueva". La nueva advocación responde a la fundación de un altar dedicado a esta santa, cuya existencia consta documentalmente en febrero de 1380 (MARTÍNEZ SANZ, M.: op. cit., p. 142) y que continuaba en su sitio a principios del siglo XVII (MATESANZ DEL BARRIO, J.: op. cit., p. 295).

41 El propio autor admite que pudieron terminarse algunos años antes (LÓPEZ MATA, T.: op. cit., p. 384)

42 ACB. LIB-38 1, 33v. 1369

43 ACB. LIB-38 1, 17v, 1369

4 ACB. LIB-38 1, 2-6. 15/12/1369.

5 ACB. V-31, 345. Medina del Campo, 13/04/1370.

46 ACB. LIB-39 2, 834. 4/05/1380

\section{EXTERIOR}

La Capilla de Santa Catalina consta de dos pisos, pero su estructura solamente es visible en su lado oriental ${ }^{47}$ (Fig. 1). El piso bajo se manifiesta exteriormente por medio de dos arcos escarzanos que sobresalen del paramento y apoyan en una ménsula central y en los contrafuertes de la capilla ${ }^{48}$. Tales arcos se muestran como simples molduras sin correspondencia con la estructura interior, donde la luz de un único arco escarzano abarca la distancia entre los contrafuertes ${ }^{49}$.

La articulación exterior del segundo cuerpo es algo más compleja. Sobre la ménsula central del piso inferior apoya una pilastra de sección trapezoidal que, a su vez, soporta un pilar gótico. Este pilar adosado está formado por una columna central y parejas de columnillas más finas a cada lado que comparten un capitel de cesta lisa y ábaco poligonal de dos boceles separados por una escocia. El arranque de este pilar coincide con el nivel del pavimento de la capilla de Santa Catalina y, por tanto, estructuralmente forma parte de ella. En este soporte central apean dos arcos apuntados poco potentes y moldurados, cuyos extremos cargan en ménsulas emplazadas en los ángulos que forman el muro y los contrafuertes. Las ménsulas son los únicos elementos que reciben decoración escultórica figurada.

Por encima de los arcos corre una moldura -con una gárgola en su punto medio- que se prolonga en derredor de los contrafuertes y delimita la composición de la fachada en dos cuerpos. El inferior está articulado en los registros superpuestos de dobles arcos, ya descritos, mientras que el superior está dominado por un gran arco ojival sin derrame que se abre en posición central. Su aspecto sobrio y recio (el tamaño de la ventana de iluminación es notablemente menor que el vano) contrasta con la liviandad de los

47 La reforma de la Capilla de San Juan Bautista en el siglo XVI ocultó por completo el lado norte. El muro meridional solamente es visible en su parte más alta como resultado de la edificación de la Capilla de Juan Estébanez y, en época reciente, de la ampliación del depósito del archivo catedralicio sobre ella.

48 Los vanos adintelados que hay bajo los arcos son de factura moderna.

49 El piso bajo de la Capilla de Juan Estébanez tiene un arco de similares características, pero ligeramente apuntado. La parte que corresponde a la Capilla de San Juan Bautista se articula con un arco escarzano bajo el que se abre una puerta de acceso al pasillo que corre bajo ella en dirección este-oeste, al que se accede desde la Capilla de Santiago por una escalera todo ello construido en el siglo XVI y que se accede desde lapilla de Sacige por pa actualnente se utiliza para la circulacionn de los visitantes de la Catedral hacia el claustro bajo. En estas dependencias declación con la actual calle Diego Porcelos (MATESANZ DEL BARRIO, J.: op. cit., pp. 122-123). Estos vanos han sido cegados con motivo de las últimas intervenciones de conservación y restauración de la Catedral. 

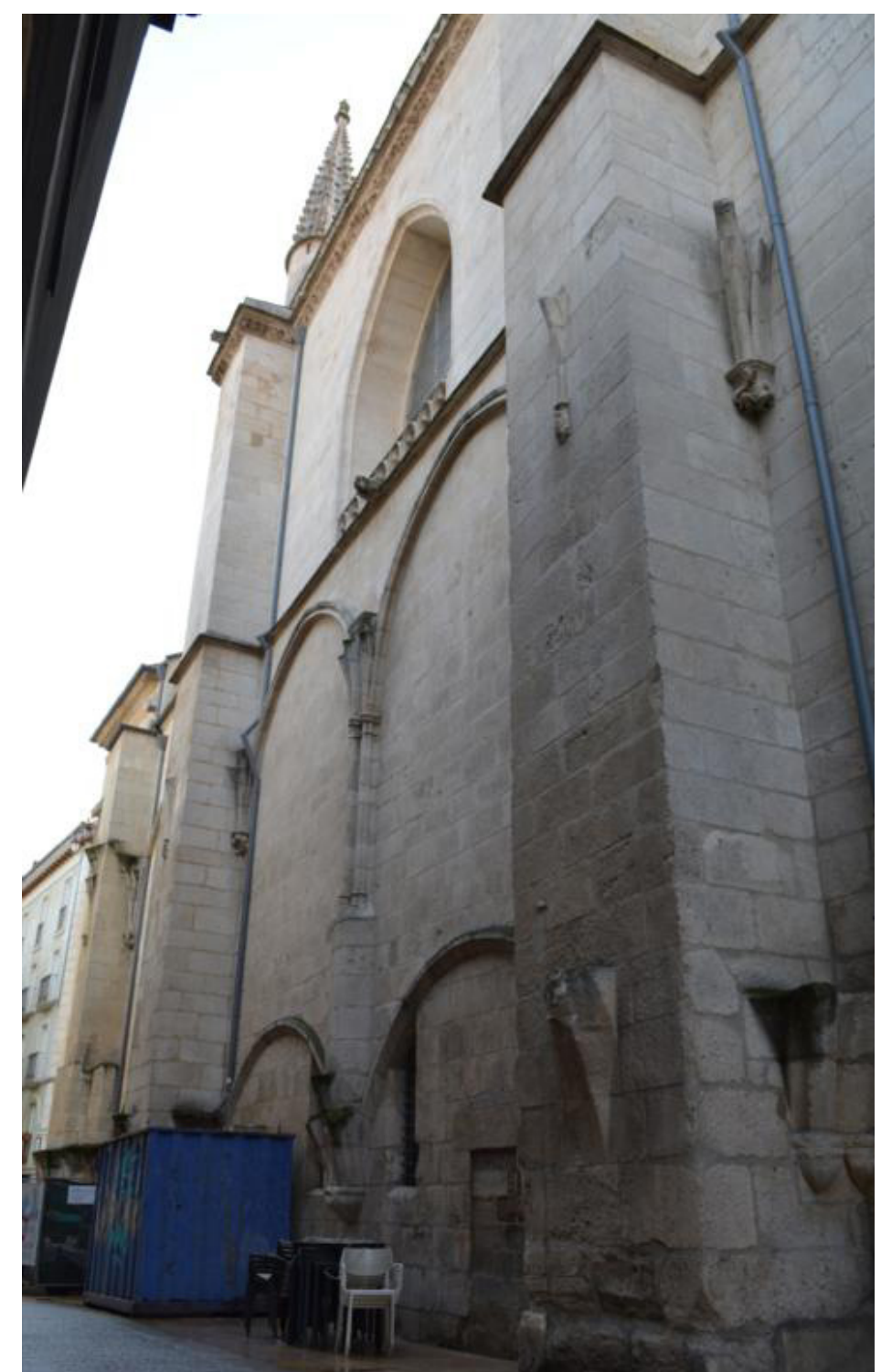

Fig. 1: Capilla de Santa Catalina, Catedral de Burgos, fachada oriental elementos arquitectónicos del cuerpo inferior. El vano tiene una sencilla moldura cóncava en su borde exterior que se desarrolla sin interrupción en el arco y las jambas. El vano está perforado por una ventana triangular de lados curvos, cobijada bajo el arco ojival ${ }^{50}$. En la parte inferior del hueco, un antepecho formado por arquillos de intradós trilobulado aporta un elemento ornamental.

El edificio se corona con cuatro torrecillas cilíndricas rematadas por esbeltos pináculos de base octogonal. En conjunto, muestran cierta consonancia compositiva con los husillos del claustro. Las torres tienen ventanitas cuadrifoliadas y los paños de los pináculos pequeñas perforaciones circulares, similares a las usadas en el tramo final de las agujas de las torres de la catedral burgalesa. Los paños están separados por filas de crochets que convergen en la cúspide. Estas torrecillas se unen en su base con un antepecho de sillería sobre el que corre una galería baja de arcos ojivales trilobulados y enjutas caladas, de composición similar al antepecho exterior del vano oriental de la capilla. Este motivo ornamental está tomado de la propia catedral burgalesa, cuya nave central y crucero se rematan con una arquería similar, situada por delante del arranque del tejado, con independencia de cómo fuera su pendiente primitiva. El motivo del siglo XIII fue ligeramente modificado acentuando el apuntamiento de los arcos y del lóbulo central. Las torrecillas y sus esbeltas agujas conforman, junto con el remate perimetral calado, un cuidado coronamiento que responde a la relevancia que se concedió a la nueva sala capitular (Fig. 2).

Las cuatro torrecillas, aunque tienen puertas, son estructuras meramente ornamentales que no sirven para acceder a la cubierta del edificio porque ninguna de ellas presenta continuidad en forma de husillo hacia la zona inferior de la capilla. Tampoco se construyó una escalera en el interior del muro. El acceso al tejado se realiza por medio de una escalera exterior doble, situada a la vista en el centro del muro occidental, constituida por una sucesión de escalones salientes, formando ambas ramas una figura triangular, estructura meramente funcional que repite las existentes detrás de las galerías que rematan los hastiales del crucero de la catedral.

50 Este tipo de vano se utilizó poco después en el muro occidental de la Capilla de Juan Estébanez, pero enriquecido con una tracería de tres triángulos de lados curvos trilobulados y otros tantos óculos trilobulados. Otra ventana triangular de lados curvos, con tres cuadrifolios, puede verse en la panda norte del claustro catedralicio. 


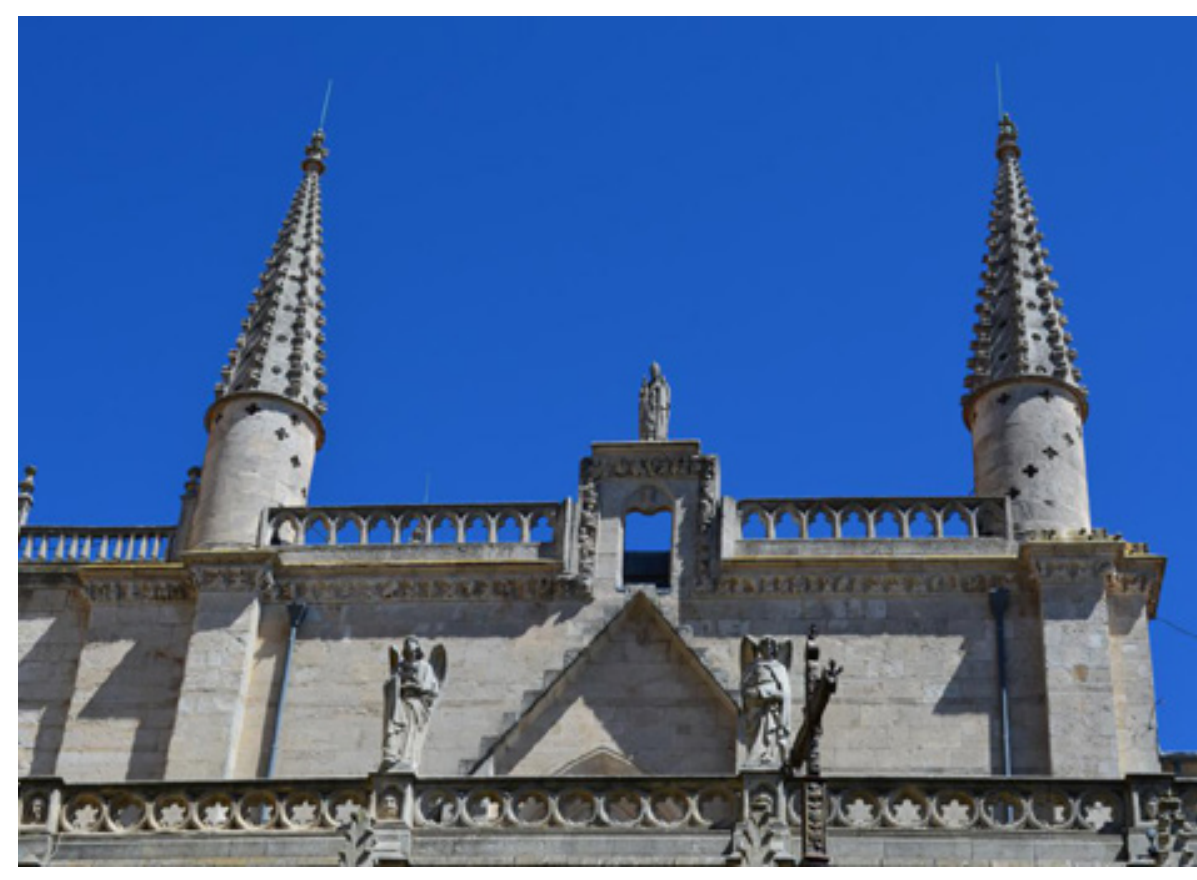

Fig. 2: Estado actual del coronamiento de la fachada occidental, Capilla de Santa Catalina, Catedral de Burgo

La disposición primitiva del tejado debió ser similar a la actual, es decir, arrancando detrás de la arquería perimetral del remate, aunque su forma y pendiente no se puedan determinar. La ausencia de husillo o escalera interior no permite un fácil acceso a la cubierta, circunstancia que pudo afectar negativamente a su conservación y con la que podrían estar relacionadas las numerosas reparaciones de que fue objeto en los siglos XVII y XVIII ${ }^{51}$. Estas intervenciones terminaron por apoyar el alero del tejado sobre la galería de arquillos, tal y como se observa en una fotografía decimonónica anterior a la restauración del claustro por Lampérez (Fig. 3). Esta disposición permite la evacuación del agua de lluvia evitando su contacto con la cobertura de fábrica de la bóveda.

51 El tejado de la Capilla de Santa Catalina se reparó en 1643, 1669, 1675, 1709, 1714 y 1722. MATESAN' DEL BARRIO, J.: op. cit., pp. 123, 295 y 313.

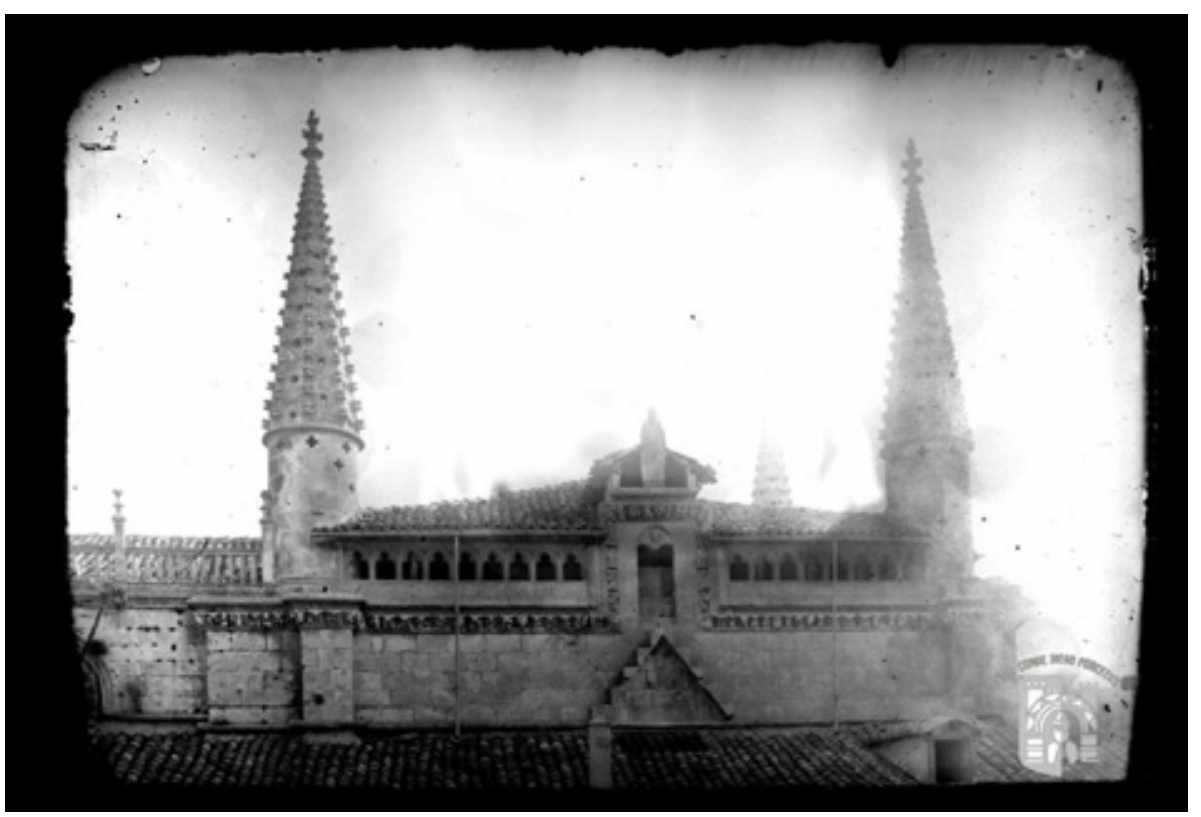

Coronamiento occidental de la Capilla de Santa Catalina de la Catedral de Burgos en su estado anterior la restauración del claustro por Vicente Lampérez. Fondo fotográfico del Instituto de Enseñanza Secundaria Conde Diego Porcelos (Burgos)

La solución que hoy vemos sustituyó a un remate anterior cuyos restos son visibles en la esquina suroeste del edificio. Consistía en pináculos en lugar de torres, situados sobre los contrafuertes, con forma de pirámide de base octogonal, flanqueados por chapiteles de menores dimensiones y base cuadrada (Fig. 4), similares en cierto modo a los que rematan los contrafuertes del crucero de la catedral. La ausencia de información escrita sobre el proceso constructivo del edificio no permite determinar el momento ni las circunstancias en que se efectuó esta reforma. El carácter meramente ornamental y la gracilidad de las torres, así como el calado de los paños de sus agujas -aun siendo su trazado muy simpleson elementos que responden a un momento más avanzado del gótico burgalés, en torno a las últimas décadas del siglo XV, en correspondencia con la apertura de nuevos vanos en los paramentos norte y sur con el fin de mejorar la iluminación de la capilla. 


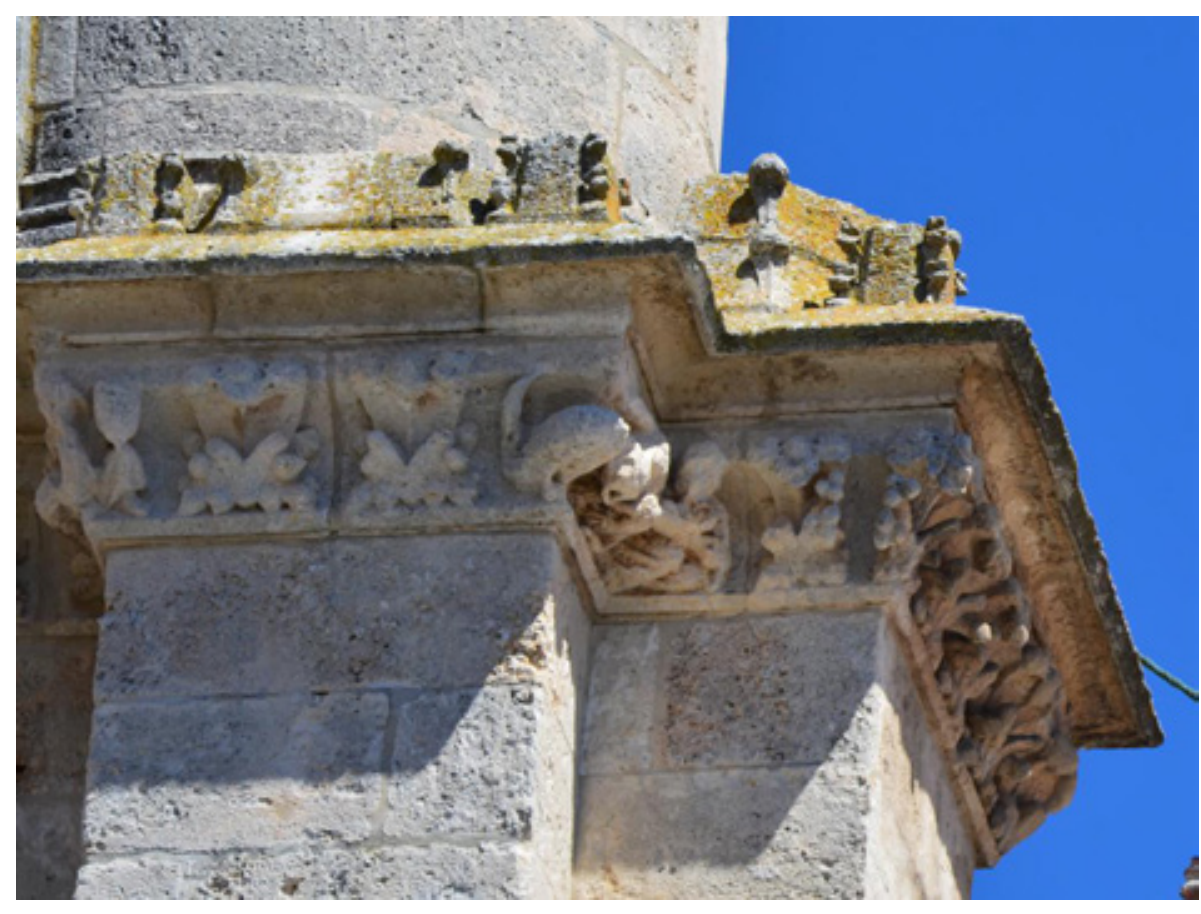

Fig. 4: Arranque de pináculos sobre los contrafuertes de la esquina suroeste, Capilla de Santa Catalina, Catedra de Burgos

Una cornisa con abundante decoración escultórica recorre muros y contrafuertes. Su estado de conservación es deficiente en algunas partes. Alternan temas vegetales -los más abundantes- y figurativos humanos y animales. La escalera exterior de acceso al tejado conduce a una puerta de arco de medio punto abierta en un murete rectangular cuyo marco decorativo se corresponde sin solución de continuidad con la cornisa de la capilla Aquí el repertorio ornamental es casi exclusivamente humano. Sobre el portillo se yergue la imagen en bulto redondo de un obispo, con báculo y mitra, alusión genérica al carácter episcopal de la promoción o tal vez, más concreta e individualizada, al promotor del edificio, don Gonzalo de Hinojosa (Fig. 2).

\section{INTERIOR}

El piso inferior de la sala capitular es de planta cuadrada y está dividido en dos espacios rectangulares de dirección norte-sur cubiertos con bóvedas cuatripartitas de nervios moldurados con un filete central entre nacelas (Fig. 5). Las claves están decoradas con sencillos motivos vegetales. El arco central, de dirección norte-sur, es muy potente y de sección pentagonal, con caras planas y lisas. Los arcos arrancan de sólidos pilares. Todos los nervios son escarzanos, en consonancia con una plementería casi plana de rampante llano que sirve de apoyo al pavimento del piso alto. En el lado sur, dos vanos comunican con el espacio situado bajo la Capilla de Juan Estébanez. Para garantizar la estabilidad de la edificación superior estos vanos se reforzaron con tres potentes arcos apuntados superpuestos que enjarjan en los pilares. En el lado norte, donde no existía piso bajo claustral, el espacio se cerró con muros de sillería bajo arcos escarzanos. El conjunto está proyectado para cumplir una función tectónica y de servicio, sin ninguna pretensión de orden estético.

El pavimento del piso alto está situado a una cota superior a la del solado del claustro, desnivel que se salva con tres gradas. Este rasgo se repite en la Capilla de Juan Estébanez, pero no en la de San Juan Bautista cuyo pavimento actual está situado a una cota ligeramente más baja que la del claustro.

El espacio interno del piso noble de la antigua sala capitular de la Catedral de Burgos se caracteriza por su centralidad, unidad y monumentalidad. Los elementos esenciales que lo conforman son la planta cuadrada y el abovedamiento ochavado. En la arquitectura tardorrománica y gótica fueron dos las soluciones que se aplicaron a las salas capitulares que, en la configuración general del edificio y su concreción en el espacio interno, combinan ambos elementos. Ambas soluciones comparten el uso de trompas, pero su diferente posición determina la configuración espacial. Las trompas se pueden emplazar a media altura del alzado generando ocho paramentos que se desarrollan verticalmente hasta alcanzar la cota de la bóveda principal. El ochavo configura el espacio y la estructura de la mitad superior del edificio, a cuya forma corresponde la bóveda. Cuando las trompas se sitúan a la altura de la bóveda, los paramentos del cuadrado de la planta se desarrollan sin solución de continuidad hasta alcanzar la cota del abovedamiento, generando un espacio aproximadamente cúbico que se combina con el cerramiento ochavado. Son pues, dos planteamientos arquitectónicos y espaciales claramente diferenciados. 


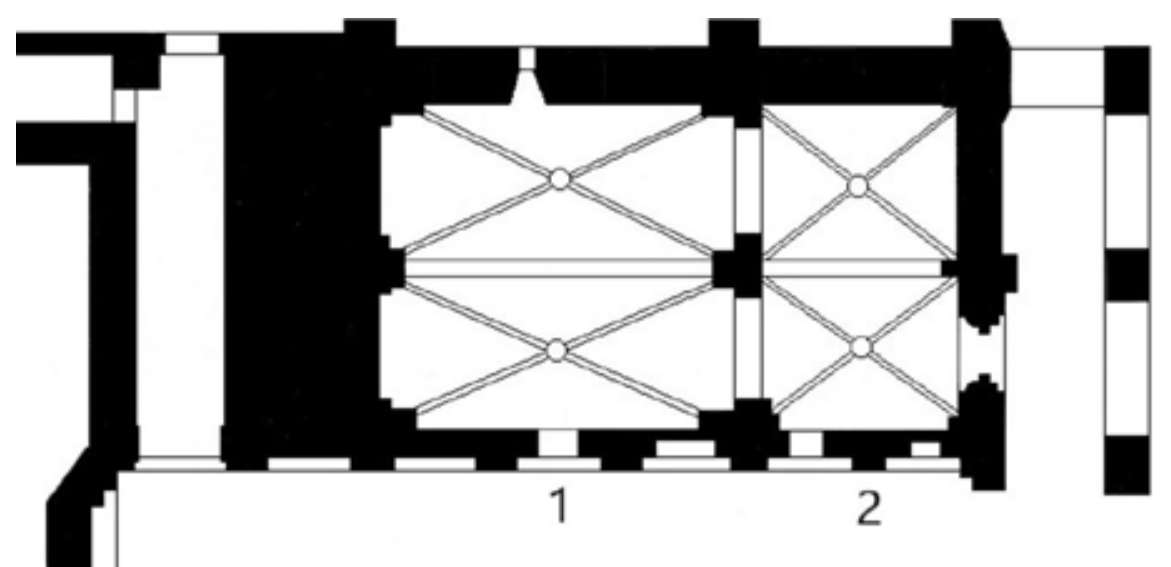

Planta baja de la panda oriental del claustro de la Catedral de Burgos. 1. Capilla de Santa Catalina. 2. Capilla del Corpus Christi (de Juan Estébanez). Modificado a partir de RICO, M.: La Catedral de Burgos. Patri monio del mundo. Burgos, 1985, p. 31

La primera fórmula, la más antigua, la encontramos a finales del siglo XII en las catedrales de Plasencia y Salamanca, cuyas bóvedas nervadas se alzan sobre tambores octogonales que asientan en trompas. El ochavo a media altura se encuentra a principios del siglo XV en la sala capitular de la Catedral de Barcelona, aunque aplicado a un espacio de planta rectangular ${ }^{52}$.

La segunda fórmula, de espacio cúbico y abovedamiento ochavado, se utilizó en salas capitulares de finales del siglo XIII y del siglo XIV, como las del monasterio de San Salvador de Oña y las catedrales de Ávila, Burgos, Pamplona y Valencia. La sala capitular de la Catedral de Oviedo, de principios del siglo XIV, representa un tipo de transición, a medio

52 Un procedimiento similar se había empleado anteriormente en la cabecera ochavada de la capilla del pacio episcopal de Tortosa promovida por el obispo Berenguer Desprats (1316-1340). MIQU

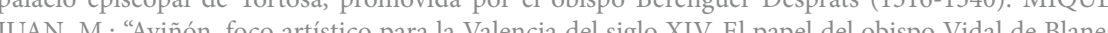
( en COSMEN, M.C, HERRAEZ ORTEGA, M. V, pEILON XOMEZ-CALCERRADA, Ma (coords): $H$ intercambio artístico entre los reinos hispanos y las cortes europeas en la Baja Edad Media. Universidad de León, 2009, pp. 321-331. camino entre ambas soluciones, pues, aunque la plementería de las trompas y de la bóveda cierran a una misma altura, debajo del arco del ochavo se construyó un arco apuntado que sirve de embocadura a la trompa; la diferencia entre ambos arcos se salvó por medio de un paramento de escasa altura, a modo de muro diafragma ${ }^{53}$.

Un segundo aspecto que conviene tener presente es la tipología de las trompas. Aunque el origen de la trompa en la arquitectura hispana medieval se pueda remontar a ejemplos islámicos, altomedievales y románicos, la tipología específica que nos interesa se desarrolla en territorio hispano en el siglo XIII. Incorpora a su estructura un nervio central de refuerzo que, siguiendo la bisectriz del ángulo recto, alcanza el arco de embocadura y, por consiguiente, divide la trompa en dos plementos simétricos. Esta solución arquitectónica se usa para ochavar las salas capitulares cuadradas del monasterio de Oña y de las catedrales de Plasencia, Salamanca, Ávila y Oviedo. Con el mismo fin se usó también en Francia tanto en salas capitulares (Santa Radegonde, Poitiers, 1210-1220) como en otros edificios (capilla de Santa Catalina de Fontevrault, $1225^{54}$ ). De igual modo, se constata su uso en la arquitectura castellana del siglo XIII, singularmente en tramos de crucero (sirvan de ejemplo las iglesias de San Vicente y San Pedro de Ávila) y cabeceras, como sucede en las capillas del crucero del monasterio de Las Huelgas de Burgos, que Karge data en torno a $1210-1215^{55}$. La trompa nervada se utiliza asociada a bóvedas de nervadura radial. En España la única excepción es la sala capitular de la Catedral de Salamanca, cuya bóveda sigue un patrón hispanomusulmán ${ }^{56}$

En la Catedral de Burgos se opera una profunda transformación de la sala capitular de planta cuadrada. En primer lugar, se renuncia a usar la trompa nervada para adoptar una bóveda plenamente gótica con forma de triángulo isósceles recto -equivalente a la mitad de un cuadrado- y tres nervios que convergen en una clave central. Estos nervios en forma de $\mathrm{Y}^{57} \mathrm{o}$ trirradiales en terminología inglesa, que Gómez Martínez identifica con

53 "Fotogrametría 3D de la sala capitular de la Catedral de Oviedo". https://sketchfab.com/3d-models sala-capitular-catedral-oviedo-photogrammetry-a0c95ee9ffd44cd696d501c8a3121182 (consultado el $15 / 07 / 2020)$.

54 DIETERICH, B.: Die architekturgeschichtliche Stellung des quadratischen stützenlosen Kapellenraumes im spanischen Skaralbau des XIV. Jhs. Disertación para obtener el doctorado de la Facultad de Filosofía de la Universidad Ludwig Maximilians de Múnich, Madrid, 1973, p. 9.

5 KARGE, H.: op, cit, p. 153

56 TORRES BALBÁS, L.: Arquitectura gótica. Ars Hispaniae, vol. VII. Editorial Plus Ultra, Madrid, 1952, p. 143 .

57 Ibid., p. 238 
el tercelete ${ }^{58}$, conforman dos plementos mayores, dispuestos simétricamente respecto a la nervadura que nace de la bisectriz del ángulo recto, y un tercero menor delimitado por el arco de embocadura de la bóveda angular (Fig. 6).

La bóveda de tres nervios tiene precedentes en la arquitectura francesa de la segunda mitad del siglo XII, cuando se usa para cubrir una capilla semicircular del deambulatorio de la catedral de Senlis. Asimismo, hay antecedentes del uso de bóvedas de forma triangular y tres nervios en la arquitectura francesa y castellana de la primera mitad del siglo XIII, en el abovedamiento del deambulatorio de la catedral de Le Mans y de la girola externa de la Catedral de Toledo, que estaba concluida en $1238^{59}$. No obstante, parece que fue en la zona del Rin, en torno a 1220, donde se comenzaron a cubrir salas capitulares cuadradas con bóvedas ochavadas mediante el concurso de bóvedas de trirradiales en los espacios triangulares de los ángulos ${ }^{60}$. A mediados del siglo XIV se utilizaron en la sala capitular del monasterio cisterciense de Eberbach (Alemania).

En Burgos, el precedente más inmediato se encuentra en la Capilla de San Antonio Abad o de la Anunciación de la catedral, donde una bóveda triangular cubre el espacio generado por la forma poligonal de las capillas radiales abiertas al deambulatorio y el muro de la capilla contigua hacia el lado occidental, que era de planta cuadrangular y se disponía perpendicularmente a la nave norte de la cabecera. La cronología de las capillas radiales septentrionales es, según Karge, más tardía que el resto, situándola en torno a $1275-1280^{61}$ Tal bóveda bien pudo tomarse como modelo para proyectar y construir la bóveda angular de la Capilla de Santa Catalina, dado que en aquella están presentes todos los rasgos que

58 GÓMEZ MARTÍNEZ, J.: El gótico español de la Edad Moderna. Bóvedas de crucería. Universidad de Valladolid, Valladolid, 1998, pp 79-80. Cita el manuscrito de Josehp Gelabert como fuente de "las formas más arcaicas de la arquitectura gótica del siglo XIII", donde se denomina tercerol a la bóveda angular triangular de tres nervios que convergen en una clave. La identificación del tercerol con el tercelete ha sido cuestionada posteriormente, habiéndose traducido el término como "capilla triangular" (RABASA DÍAZ, E. (ed.): El manuscrito de cantería de Joseph Gelabert titulado Verdaderas traçes del Art de picapedrer: transcripción, traducción, anotación e ilustración del texto y los trazados. Colegio Oficial de Arquitectos de las Islas Baleares-Fundación Juanelo Turriano, Madrid, 2011, p. 392. https://issuu.com/ juaneloturriano/docs/gelabert_completo_reducido (consultado el 4/09/2020).

59 NICKSON, T: "La Catedral: su Historia Constructiva", en La Catedral Primada de Toledo. Dieciocho siglos de Historia. Diario de Burgos-Promecal, 2010, pp. 148-161.

60 WILSON, Ch. The Gothic Cathedral. The Architecture of the Great Church, 1130-1530. Thames and Hudson, London, 1990, pp. 227-229.

61 KARGE, H.: op. cit., p. 243

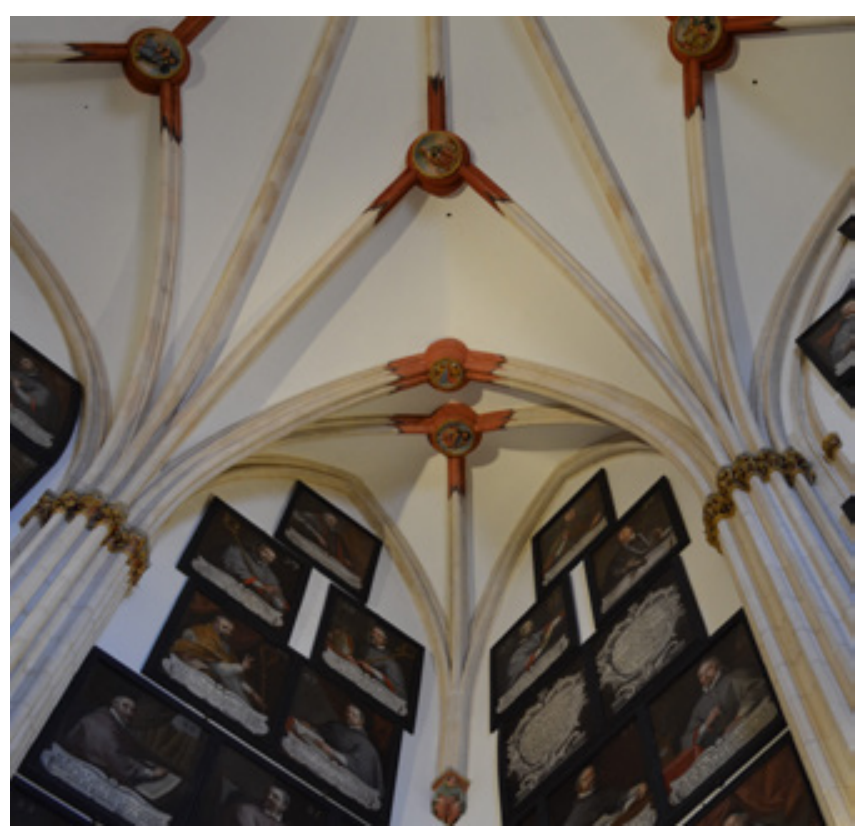

Fig. 6: Bóveda del ángulo noreste, Capilla de Santa Catalina, Catedral de Burgos

definen a esta, no solamente en cuanto a forma y disposición de los nervios, sino incluso en lo relativo a los apoyos porque, en ambos casos, la ménsula donde apoya el nervio centralestá situada a la altura de los capiteles de los pilares que reciben el arco de embocadura. El mismo tipo de bóveda angular se usa en la Capilla Barbazana de la Catedral de Pamplona y la Capilla del Santísimo Cáliz de la Catedral de Valencia, antigua sala capitular del templo.

Este elemento arquitectónico se difunde en los siglos XIV y XV, tanto en el gótico castellano como en el mediterráneo. En la Catedral de Toledo sirvió para ochavar las capillas funerarias de San Ildefonso -donde en 1372 fue sepultado el cardenal Gil de Albornoz-, de San Blas -terminada en 1399, año en el que falleció su promotor, el arzobispo Pedro Tenorio- y de Santiago, proyectada para don Álvaro de Luna en 1430 y concluida hacia $1449^{62}$. En el área burgalesa, está presente en la capilla mayor del monasterio de San Salvador de Oña. Muy relacionada con esta obra está la capilla mayor de la iglesia de Santo Tomás de Arnedo (La 
Rioja) ${ }^{63}$. Más adelante volveremos sobre estos dos edificios. En el ámbito mediterráneo destacan las salas capitulares del monasterio de Santa María de Benifassà (Castellón) y de la catedral de Valencia, así como la capilla episcopal de Tortosa, obras del siglo XIV, y la sala capitular de la catedral de Barcelona, del siglo XV.

La bóveda central, construida en piedra, es el elemento de la Capilla de Santa Catalina que más interés concita por su dibujo en estrella de ocho puntas (Figs. 7 y 8 ). El espacio central del abovedamiento es octogonal en virtud de las bovedillas angulares nervadas, cuyos arcos de embocadura se combinan con la zona central de los cuatro muros para configurar el perímetro de una gran bóveda de crucería estrellada. Su estructura nervada se asienta en ocho apoyos. De cada uno de ellos arrancan tres nervios que, combinados unos con otros, proporcionan al trazado forma de estrella de ocho puntas. Los puntos de convergencia de los terceletes se señalan con una clave ligada por un nervio recto con el polo central, que es de mayor tamaño y donde converge la figura geométrica. Se dibuja así una bóveda de nueve claves. A estas hay que sumar las claves de las bóvedas triangulares de las esquinas y las claves situadas en los arcos de embocadura de estas, resultando una abovedamiento de diecisiete claves. Este es uno de los rasgos diferenciadores de la bóveda burgalesa, cuyo origen podría encontrarse en las capillas del crucero de la iglesia del monasterio de Las Huelgas, donde se usan estas claves secundarias en los nervios de embocadura de las trompas nervadas de los ángulos. La Capilla Barbazana de la catedral de Pamplona y la sala capitular de la catedral de Valencia responden al tipo de bóveda de trece claves que la arquitectura tardogótica consagra definitivamente tanto en Castilla como en Aragón ${ }^{64}$.

El origen del diseño de la bóveda estrellada de ocho puntas podría encontrarse en las salas capitulares inglesas centralizadas construidas desde finales del siglo XII en el suroeste de Inglaterra y Gales bajo los auspicios de los cistercienses, a quienes, asimismo, se atribuye su difusión en el continente, especialmente en la zona del Rin ${ }^{65}$, aunque también en España ${ }^{66}$

62 FRANCO MATA, A.: "Las Capillas", La Catedral Primada de Toledo. Dieciocho siglos de Historia. Diario de Burgos-Promecal, 2010, pp. 180-225.

63 ARRUE UGARTE, M. B.: "El sistema hallenkirchen' en La Rioja: de los modelos conservados al singular ejemplo de San Millán de la Cogolla”, en LACARRA DUCAY, M.C. (coord.): Arquitectura religiosa de siglo XVI en España y Ultramar. Institución Fernando el Católico, Zaragoza, 2004, pp. 115-158 (p. 130). ZARAGOZÁ CATALÁN A. e IBÁÑEZ FERNÁNDEZ J: "Hacia una historia de la arquitectura en la

64 Corona de Aragón entre los siglos XIV y XV a partir de los testeros de los templos. Ábsides construidos, ábsides proyectados e ideales y ábsides sublimes", Artigrama, n. 29,2014 , pp. 261-303.

65 WILSON, Ch.: op. cit., pp. 227-229.

66 DIETERICH, B.: op. cit., pp. 24-25.

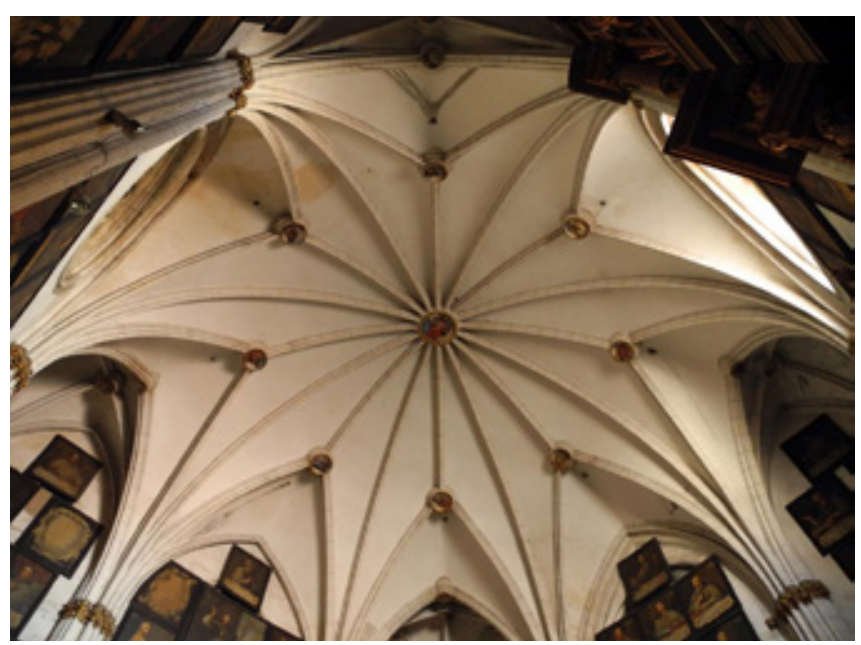

Fg. 7: Bóveda de la Capilla de Santa Catalina antes de su restauración en 2016 Catedral de Burgos. José Antonio Gárate Alcalde

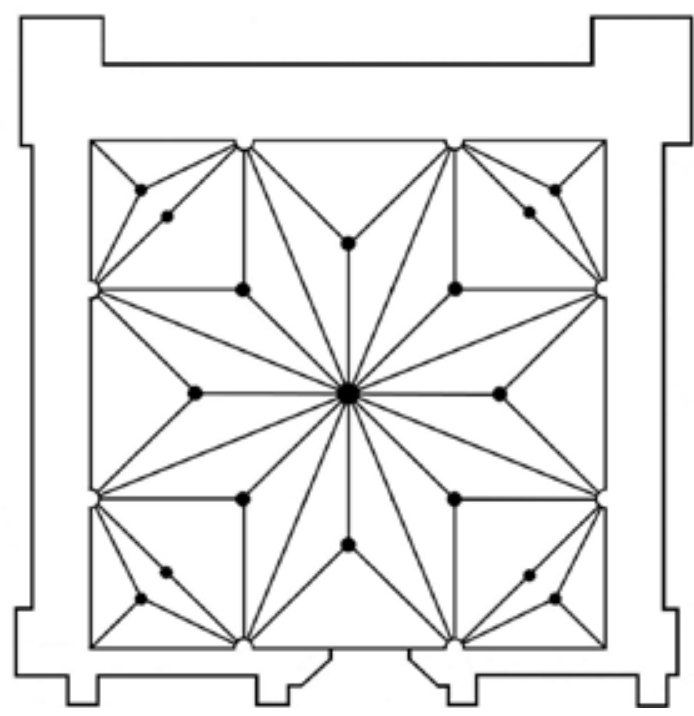

Fig. 8: Planta de la Capilla de Santa Catalina, Catedral de Burgos 
El esquema en forma de estrella de ocho puntas de las bóvedas de paraguas de las salas capitulares de la abadía de Westminster en Londres y de las catedrales de Lichfield y de Salisbury, de mediados del siglo XIII ${ }^{67}$, se usó para abovedar la sala capitular de la abadía cisterciense de Eberbach a mediados del siglo XIV, si bien aquí se aplicó a un espacio de planta cuadrada -no octogonal como el modelo inglés- y se incorporaron en los ángulos bóvedas de trirradiales, que carecen de precedentes ingleses.

El abovedamiento de la Capilla de Santa Catalina, trazado presumiblemente a principios del siglo XIV, reproduce el esquema que se aplicó a la sala capitular de Eberbach, pero prescinde del soporte central de esta y de los modelos ingleses. Aunque en Inglaterra también se pueden encontrar posibles modelos de los espacios centrales hispanos sin soportes centrales, como la sala capitular Catedral de Southwell (hacia 1290-1300), octogonal y con bóveda de 9,44 m de diámetro, cuando las dimensiones aumentan el abovedamiento de piedra se reemplaza por estructuras de madera, como sucede en la sala capitular de la Catedral de York, lo que constituye una diferencia sustancial con las monumentales bóvedas pétreas de las capillas Barbazana ${ }^{68} \mathrm{y}$ de Santa Catalina, que cubren, respectivamente, espacios cuadrados de 14,20 y 13 metros de lado.

La nueva sala capitular de la Catedral de Burgos destaca no solamente por la ausencia de soporte central sino por la aplicación de un concepto espacial radicalmente distinto, que alza la bóveda a gran altura configurando un espacio unitario, amplio y diáfano. Este mismo concepto espacial se aplicó a otros edificios germanos de soportes centrales con bóvedas en forma de estrella y bóvedas angulares de nervios en Y, como la Briefkapelle de la iglesia se Santa María de Lübeck, que se comenzó en $1310^{69}$

Cuando se compara el esquema compositivo de las bóvedas de las salas capitulares inglesas, de Eberbach y de Burgos, los parecidos son evidentes, pero debemos tener presente la enorme diferencia estructural que separa a las bóvedas de soporte central de las bóvedas de apoyos perimetrales. En realidad, el diseño de la forma de estrella de ocho puntas resulta de la suma de terceletes en los ángulos de una bóveda octogonal de nervaduras radiales y

67 Son numerosos los autores que señalan como precedente continental más antiguo de la bóveda estrellada de ocho puntas a la bóveda de estas características dibujada en el cuaderno de Villard de Honnecout pensada para un soporte centramo perada para un soporte centra col ferencia de estas, carece de nervios diagonales. Vid. BARRÓN GARCÍA, A.: op. cit., pp. 221-222 y nota 2 68 DIETERICH, B.: op. cit., p. 2

69 FRANKL, P.: op. cit., p. 286. sus correspondientes ligaduras con el polo central. Los terceletes se habían usado, antes que en las salas capitulares inglesas, en la nave de la catedral de Lincoln hacia $1220-1235^{70}$, y en el continente se encuentran hacia 1264 en un lugar tan destacado como el crucero de la catedral de Amiens ${ }^{71}$. Su introducción en el territorio hispano -cuando menos su difusiónse puede atribuir a los maestros que trazaron las bóvedas de la Capilla de Santa Catalina y la Capilla Barbazana.

Respecto a la posible relación del abovedamiento de la Capilla de Santa Catalina con modelos ingleses conviene señalar que, al margen de la difusión que estos pudieron tener en el área centroeuropea, Burgos mantuvo una activa relación comercial con Inglaterra en la segunda mitad del siglo XIII y primera del XIV y algunos de los más destacados mercaderes burgaleses sirvieron de enlace entre las coronas inglesa y castellana en asuntos diversos ${ }^{72}$.

Otro factor a tener en cuenta como potencial origen o inspiración de la capilla burgalesa son los viajes europeos de don Gonzalo de Hinojosa. Antes de que en septiembre de 1316 promoviese la construcción de la sala capitular realizó dos. Como obispo de León participó en el Concilio de Vienne (octubre de 1311-mayo de 1312) convocado por el papa Clemente V para disolver la Orden del Temple ${ }^{73}$. Siendo ya obispo de Burgos, a cuya silla había sido preconizado el 12 de abril de 1313, viajó a Aviñón, donde el 4 de noviembre de 1314 recibió el encargo del papa Clemente $\mathrm{V}$ de reunir a los obispos para poner solución al entredicho que pesaba sobre el reino por causa del cobro de las tercias decimales ${ }^{74}$. Sendos viajes tienen como nexo la corte papal de Aviñón, importante centro artístico del siglo XIV que se ha puesto en relación con el obispo Vidal de Blanes, promotor de la sala capitular de la Catedral de Valencia, y con Andreu Juliá, el maestro a quien se atribuye su construcción ${ }^{75}$.

Antes de que se pudieran iniciar las obras de su capilla en 1325, don Gonzalo de Hinojosa estuvo en París en dos ocasiones. En 1317 fue enviado como embajador ante el rey de Francia para tratar un posible matrimonio de la princesa Isabel y el rey don Alfonso ${ }^{76}$. En

70 Ibid., p. 226

71 BARRÓN GARCÍA, A.: op. cit., p. 221

72 RUIZ, T. F.: "Mercaderes castellanos en Inglaterra", en RUIZ, T. F.: Sociedad y poder real en Castilla (Burgos en la Baja Edad Media). Ed. Ariel, Barcelona, 1981, pp.199-224.

73 ORDÁS DÍAZ, P.: op. cit.

4 ZARAGOZA PASCUAL, E.: op. cit.

5 MIQUEL JUAN, M.: op. cit.

76 ORDÁS DÍAZ, P.: op. cit. 
1320 la reina María de Molina, tutora de Alfonso XI, le envió para tratar la devolución de la dote de la infanta Isabel, hija de Sancho IV y la misma reina, al haber fallecido sin hijos el duque Juan III de Bretaña, con quien se había casado en segundas nupcias. Durante su estancia en París, Gonzalo de Hinojosa mantuvo contactos con el área renana al haber obtenido del rey Felipe IV de Francia una súplica para que el arzobispo de Colonia donara a la catedral de Burgos dos cuerpos de las Once Mil Vírgenes, volviendo a Burgos con las reliquias de las santas Victoria y Gerasina ${ }^{77}$.

Los soportes sobre los que se asienta la bóveda de la Capilla de Santa Catalina son pilares con seis columnillas que reciben los nervios que apoyan en cada uno ellos (dos formeros, uno de embocadura de la bóveda angular, un crucero y dos terceletes) (Fig. 9). Los capiteles están decorados con motivos vegetales y conservan la entidad individual de sus ábacos aun cuando, debido a su proximidad, formen una serie sin solución de continuidad. Los pilares articulan plásticamente los paramentos, definiendo secciones verticales de sentido ascensional. Este sistema de soportes es un rasgo específico de la sala capitular burgalesa. En la Capilla Barbazana de la Catedral de Pamplona se usaron ménsulas situadas en el arranque de los nervios, tipo de soporte que repite la antigua sala capitular de la Catedral de Valencia.

Sin duda, el abovedamiento de la Capilla de Santa Catalina determina la disposición de los soportes, pero éstos no están solamente pensados como elementos arquitectónico subordinados a aquel, sino que cumplen la función de explicitar un programa escultórico al que se concede un valor de primer orden por medio de ménsulas ricamente decoradas y situadas a unos dos metros y medio del pavimento, quedando expuestas a una fácil y detallada contemplación. El aspecto general más destacado de su programa iconográfico es su carácter profano, relacionado con la monarquía castellana ${ }^{78}$-en consonancia con la adopción de la heráldica castellano-leonesa como motivo ornamental de la portada- y con la cultura caballeresca ${ }^{79}$. La presencia de soportes sobre ménsulas relaciona la sala capitular catedralicia con la arquitectura cisterciense.

77 FLOREZ, E.: España Sagrada. Tomo XXVI. Madrid, 1776, p. 347.

78 Esta relación ya fue destacada a principios del siglo XX (SERRANO FATIGATI, E.: "Rápida ojeada a la escultura castellana de diversas épocas", Boletín de la Sociedad Española de Excursiones, Año XVI (1918), tercer trimestre, pp. 227-230).

79 Una interpretación del conjunto en relación con la historia de Flores y Blancaflor en SÁNCHEZ AMEIJEIRAS, R.: "History and Stories of Love and Conversion in Fourteenth-Century Burgos", Hispani research journal, Vol. 13, n. ${ }^{\circ}$ 5, octubre 2012, pp. 449-467. El estudio del programa decorativo de 1 Capilla de Santa Catalina forma parte de un trabajo actualmente en proceso de elaboración.

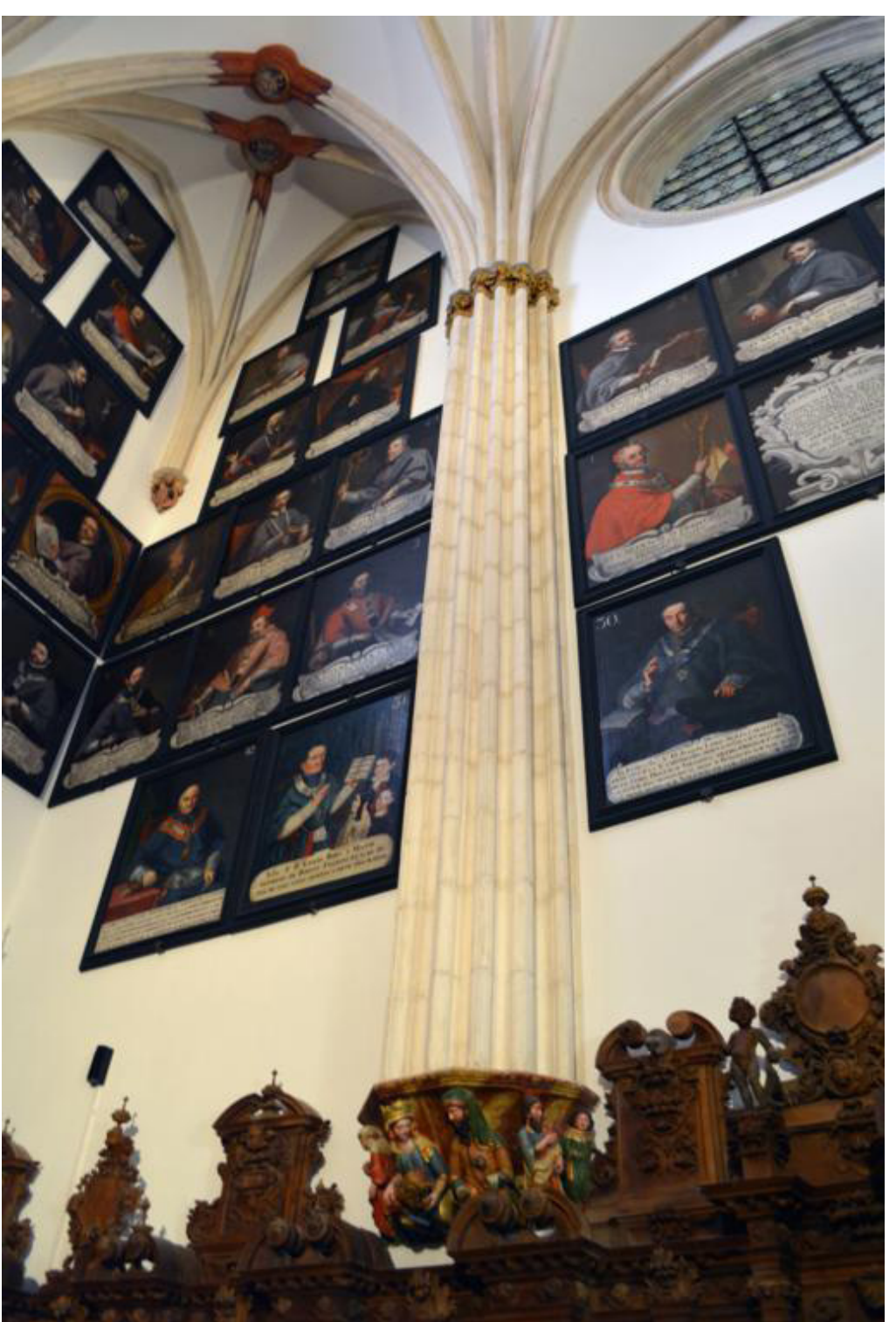

9: Pilar adosado, lado sur de la Capilla de Santa Catalina, Catedral de Burgos 
Actualmente la capilla tiene cuatro vanos situados en la parte alta de cada uno de los paramentos centrales de cada lado, pero solamente las ventanas del muro oriental y occidental formaron parte del proyecto inicial. La escasa iluminación de la capilla respondería al predominio del macizo sobre el vano que caracteriza a la arquitectura castellana del siglo $\mathrm{XIV}^{80}$. La ventana oriental se ajusta rigurosamente al intradós del arco de la bóveda. Tiene forma de triángulo de los lados curvos, tipología que se usa también en la sala capitular de Valencia. Perfora el grosor del muro sin derrame y está circunscrito por dos boceles con un junquillo central separados por media caña. El intradós es liso y sin derrame, decorado únicamente por dos boceles con listel central que corren próximos a sus extremos (Fig. 10).

La ventana del muro occidental es de menores dimensiones y está tapiada, pero se abría bajo un arco apuntado, visible también desde el exterior bajo los peldaños de la escalera de acceso a la cubierta. Su cegamiento tuvo que coincidir con la construcción de un tercer piso claustral que la restauración de Vicente Lampérez eliminó. Un paso elevado o pontido lo comunicaba con el palacio episcopal. Don Alonso de Cartagena (1435-1456) ocupó las pandas sur y oeste, aunque la mayor parte de la información del siglo XV relativa a la distribución y usos del tercer piso del claustro corresponde al episcopado de Luis de Acuña (1456-1495) ${ }^{81}$. Sin embargo, poco se sabe de las características arquitectónicas del primitivo sobreclaustro ${ }^{82}$, aunque sí que en tiempo de este prelado las dependencias que lindaban con las capillas de Santa Catalina y de Juan Estébanez eran más bajas que las situadas en otras pandas, lo que impedía su uso habitacional ${ }^{83}$.

Las ventanas de los muros norte y sur tienen forma circular y su perfil y molduración difieren mucho de la ventana oriental, por lo que pudieron que ser abiertas para mejora la iluminación después de que se cegase el vano occidental, tal vez formando parte de una intervención de mayor envergadura que incluyó la reforma del coronamiento del edificio con la construcción de las cuatro torres y sus agujas. El óculo norte se aloja bajo un arco que apoya en dos columnillas separadas de los pilares adosados. Este arco solamente se

80 YARZA LUACES, J.: Baja Edad Media. Los siglos del gótico. Editorial Sílex, Madrid, 1992, p. 102.

81 PAMPLIEGA PAMPLIEGA, R.: Pontido y otras dependencias de la Catedral de Burgos, Burgos, 2005.

El sobreclaustro se rehízo en el siglo XVII. El resultado de esta intervención fue el que se derribó en la restauración que Vicente Lampérez dirigió desde 1889. CARRERO SANTAMARÍA, E.: "Restauración monumental y opinión pública. Vicente Lampérez en los claustros de la catedral de Burgos", LOCVS

82 CARRERO SANTAMARÍA, E.: "Restauración monumental y opinión pública. Vicente Lampérez en los claustros de la catedral de Burgos", LOCVS AMOENVS, 3, 1997, pp. 161-176.

83 PAMPLIEGA PAMPLIEGA, R.: op. cit., p. 81 .

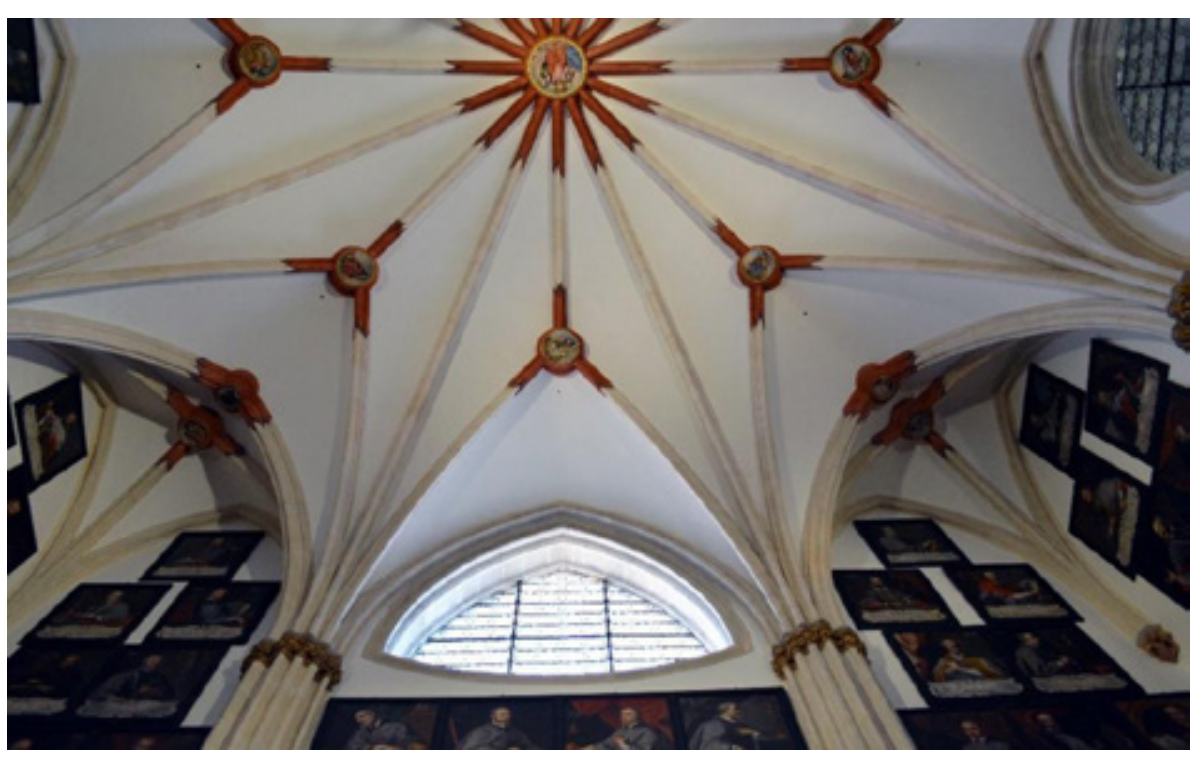

Fig. 10: Muro oriental y bóveda, Capilla de Santa Catalina, Catedral de Burgos

encuentra en este paramento. El vano fue cegado por la capilla de San Juan Bautista cuando se reconstruyó en 1524-1534 $4^{84}$ y se elevó su altura hasta la cota de la Capilla de Santa Catalina. El cegamiento del vano es coherente con su existencia previa a estas obras. El óculo del lado sur, cuya molduración es más compleja con dos boceles dominantes en la parte media del derrame, siguió cumpliendo su función de iluminación por la diferencia de altura respecto a la Capilla de Juan Estébanez ${ }^{85}$, aunque pudo verse afectado por la construcción en 1596 del archivo catedralicio sobre esta misma capilla y la nueva sala capitular ${ }^{86}$ acabó afectando también a este vano. En 1714 se repararon las vidrieras de la capilla de Santa Catalina ${ }^{87}$ momento en el que se debieron armonizar los diseños ornamentales de los tres vanos ${ }^{88}$.

84 LÓPEZ MATA, T.: op. cit., p. 308

85 En 1698 y 1699 se repararon el óculo y su vidriera. MATESANZ DEL BARRIO, J.: op. cit., p. 296.

86 PAMPLIEGA PAMPLIEGA, R.: op. cit., p. 59 .

87 MATESANZ DEL BARRIO, J.: op. cit., p. 313

88 En la restauración de 2016, las vidrieras se rehicieron siguiendo el patrón existente. NUEVE RESTAU RA S.L.: "Capilla de Santa Catalina, 2016. Informe". 
El arzobispo don Manuel Francisco Navarrete promovió la transformación de la Capilla de Santa Catalina en sacristía. Entre 1711 y 1714 se retiró la sillería anclada a la pared que servía para las reuniones del Cabildo ${ }^{89}$ y se sustituyó por un mobiliario adaptado a la nueva función de la dependencia. Asimismo, se acometieron intervenciones de orden arquitectónico, tales como la sustitución del pavimento primitivo por un nuevo losado y el encalado de los muros ${ }^{90}$

\section{LA CAPILla DE SANTA CATAliNA Y LA CAPILla BARBAZANA}

La relación de similitud existente entre las capillas de Santa Catalina de la Catedral de Burgos y la Capilla Barbazana de la Catedral de Pamplona son evidentes y ha sido puesta de manifiesto en numerosas ocasiones. Ante la falta de documentación escrita y de una cronología precisa del proceso constructivo de ambos edificios es muy difícil que se pueda determinar con seguridad cuál de ellas influyó en la otra. La cuestión, por tanto, no quedará resuelta aquí, pero algunos datos y reflexiones pueden servir para fundamentar la hipótesis de que fuera la capilla burgalesa la que sirviese de modelo a la de Pamplona.

En primer lugar, hay que considerar que la bóveda de la Capilla Barbazana fue incorporada a un edificio preexistente. En una primera fase, en torno a 1280-1318, se construyeron la cripta, los muros y la puerta de la capilla. La bóveda y el coronamiento exterior corresponden a una segunda fase constructiva, desarrollada durante el episcopado de Arnaldo de Barbazán (1318-1355) ${ }^{91}$. Por el contrario, la Capilla de Santa Catalina obedece en su totalidad a un proyecto de nueva planta ejecutado en una sola campaña constructiva y, lo que es más importante, su configuración, desde la base hasta el abovedamiento, tuvo que estar perfectamente definida desde sus inicios debido a la tipología de los soportes (pilares adosados) y su exacta correlación con el diseño de la bóveda. Es probable que el obispo don Gonzalo de Hinojosa dispusiese de una traza arquitectónica en septiembre de 1316, cuando se concierta con el Cabildo para adquirir el solar para la nueva sala capitular

89 MARTÍNEZ SANZ, M.: op. cit., p. 143.

90 MATESANZ DEL BARRIO, J.: op. cit., pp. 297-314

91 FERNÁNDEZ LADREDA, C. y LORDA, J.: "Dependencias claustrales. Capilla Barbazana, refectorio, cocina y dormitorio", en NAVALLAS REBOLÉ, A. (dir.): La Catedral de Pamplona. 1394-1994. Caja de Ahorros de Navarra, Pamplona, 1994, T. I, pp. 219-244. y que, por consiguiente, la bóveda burgalesa estuviera proyectada antes incluso del nombramiento de don Arnaldo de Barbazán como obispo de Pamplona, que tiene lugar en 1318. Además, los primeros años de su mandato no fueron favorables al emprendimiento de empresas artísticas. El obispo contrajo enormes deudas con motivo de la jura del rey Felipe el Luengo y el convenio de cesión a la corona de la jurisdicción temporal de la iglesia en los cuatro barrios de la ciudad, acordado en septiembre de 1319 en París $^{92}$.

El principal paralelismo entre las dos capillas es el diseño general de su abovedamiento que resulta novedoso tanto por la bóveda central como por las bóvedas de los ángulos. No obstante, existen elementos diferenciadores. En primer lugar, hay que destacar que la bóveda de la sala capitular de Burgos es de diecisiete claves y la de Pamplona de trece. En segundo lugar, la primera utiliza como soporte pilares adosados con columnillas y ménsulas la segunda. En Pamplona se optó por el uso de ménsulas para poder adaptar fácilmente la compleja estructura de la bóveda al edificio preexistente, de paramentos lisos. En Burgos, los pilares, que apoyan en ménsulas próximas al pavimento, formaron parte del edificio desde el inicio de su construcción. La ubicación de los soportes responde, como es obvio, a la estructura del abovedamiento, de modo que se puede concluir que su diseño estuvo ya definido en el proyecto inicial de la capilla. En este mismo sentido se puede interpretar la perfecta integración de los contrafuertes, dispuestos perpendicularmente al muro oriental. Los contrafuertes de la capilla Barbazana se disponen oblicuamente, buscando una rigurosa correspondencia con la estructura nervada de la bóveda, con la finalidad de contrarrestar los empujes, no previstos inicialmente, que esta generaba ${ }^{93}$. Por último, aunque en ambas capillas se utiliza la misma bóveda angular para ochavar el cuadrado, en la Capilla Barbazana la ménsula en la que apoya el nervio central está a mayor altura que las ménsulas en las que apoyan los nervios del arco de embocadura, mientras que en la Capilla de Santa Catalina la ménsula de la esquina y los capiteles de los pilares están a la misma altura.

No es posible determinar cómo se habría producido la transferencia del modelo de bóveda entre Burgos y Pamplona. En la época de construcción de ambos edificios no existe una relación intensa entre ambas sedes episcopales y la política del reino de Navarra está

92 La liquidación delas deudas se prolongó hasta 1332 Aún en 1334 Arnaldo de Barbazán alegé la pobreza de la mesa epicopal, cury renta no pasba de las 4000 librs, para conseguir del papa la uniona ha

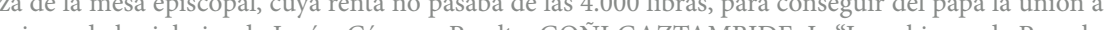

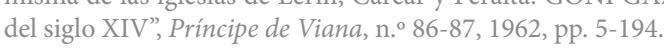
93 FERNÁNDEZ LADRERA, C. y LORDA, J.: op. cit. 
claramente orientada hacia Francia. No obstante, la pertenencia del monasterio de Santa Marina de Cabia a la Catedral de Pamplona pudo ser motivo de paso por Burgos de algún agente de esta. Con motivo de la muerte de varios vecinos de Alfaro, el obispo Arnaldo de Barbazán fue enviado por el gobernador de Navarra a Alcalá de Henares para solicitar del monarca castellano una solución pacífica, a lo que este accedió. El mismo día, 25 de febrero de 1347, Alfonso XI ofreció protección al obispo y a cualquier canónigo que tuviese la casa de Cabia para que pudieran andar libres sin pagar otros derechos que los reales ${ }^{94}$ lo que indica la existencia de un movimiento de personas entre esta localidad y Pamplona ruta que necesariamente pasaba por la ciudad de Burgos. ¿Fue entonces cuando el obispo de Pamplona conoció la obra de la Capilla de Santa Catalina adoptando el diseño de su abovedamiento para su capilla?

Ambos edificios son de planta cuadrada y de dimensiones monumentales, aunque es mayor la Capilla Barbazana, con 14,20 metros libres de lado, que la Capilla de Santa Catalina de 13 metros $^{95}$. Esta última medida reproduce un patrón métrico que se había utilizado anteriormente en la catedral de Burgos, basado en la vara burgalesa (M) mayorada por $\sqrt{ } 2^{96}$, siendo equivalente a $11 \cdot \mathrm{M} \sqrt{ } 2$.

Ambas capillas comparten la configuración de dos pisos, estructura que se ha relacionado con el Heroon antiguo, el martyrium paleocristiano y la capilla cementerial medieval, tipología con la que estaría relacionada la capilla del hospital de peregrinos de Roncesvalles. Asimismo, existe una posible conexión entre la estructura de dos pisos de la Capilla Barbazana y las capillas del palacio feudal germano de época románica ${ }^{97}$.

En espacios centralizados hispanos el doble piso se ha relacionado con una función funeraria y precedentes prerrománicos ${ }^{98}$. En la Capilla Barbazana se ha explicado por la primitiva función funeraria del edificio ${ }^{99}$, llegando a ser considerada como prototipo de

94 GOÑI GAZTAMBIDE, J.: op. cit., p. 80

95 RICO, M.: La Catedral de Burgos. Patrimonio del mundo, Burgos, 1985, p. 438

96 GARCÍA ORTEGA, A.J.: "Tipo, tamaño y medida en la arquitectura gótica. El foco burgalés (ss. XIII-XIV)", en EGA. Expresión Gráfica Arquitectónica, Universidad Politécnica de Valencia, n. ${ }^{17}, 2012$, pp. 210-219. https://doi.org/10.4995/ega.2011.929.

97 DIETERICH, B.: Die architekturgeschichtliche Stellung des quadratischen stützenlosen Kapellenraumes im spanischen Skaralbau des XIV. Jhs. Disertación para obtener el doctorado de la Facultad de Filosofí de la Universidad Ludwig Maximilians de Múnich, Madrid, 1973, pp. 11-19.

98 BANGO, I., BARBÉ-COQUELIN DE LISLE, G., CAAMAÑO, M.: Historia de la arquitectura española una tipología de capilla funeraria hispana de los siglos XIV y XV caracterizada por su ubicación en el claustro y su carácter autónomo respecto al templo, el plan central y el uso de formas octogonales en planta o abovedamiento ${ }^{100}$. Como alternativa a esta interpretación se ha propuesto la influencia de las capillas-torre del Mediodía francés atendiendo a la estrecha relación con esta región del obispo Arnaldo de Puyana (1310-1316) ${ }^{101}$, que pudo intervenir en su construcción ${ }^{102}$. Desde este punto de vista, la Capilla Barbazana habría sido construida principalmente para servir de sala capitular ${ }^{103}$, aunque el obispo Arnaldo de Barbazán la eligiera para emplazar su sepulcro exento y su cripta acabara sirviendo como lugar de enterramiento de obispos y canónigos.

La vinculación de la estructura de doble piso de la Capilla de Santa Catalina a su función funeraria se podría sustentar en el ofrecimiento del obispo Gonzalo de Hinojosa para que sirviera al Cabildo de Burgos como lugar de enterramiento. No obstante, hay que tener presente el desnivel topográfico del lugar que, en el momento de proyectar y edificar el claustro, había impuesto la necesidad de elevarlo sobre un piso inferior para situarlo a la altura del templo catedralicio. En consecuencia, la estructura de doble claustro determino la configuración en dos pisos de las capillas de Santa Catalina y de Juan Estébanez, que muy probablemente sería la misma en ambas sin atender a una finalidad funeraria. Para la Capilla Barbazana de la Catedral de Pamplona, la función meramente constructiva de su cripta -salvar el desnivel del terreno igual que en Burgos- podría explicar asimismo su existencia ${ }^{104}$

Barcelona, 1985, t. II, p. 555

99 BANGO TORVISO, I, BARBÉ-COQUELIN DE LISLE, G, y CAAMAÑO MARTÍNEZ J.M.: Histor de la arquitectura española, Barcelona, 1985, t. II, p. 554, citado en FERNÁNDEZ LADREDA, C. LORDA, J.: op. cit.

100 MARÍAS, F.: El largo siglo XVI. Los usos artísticos del Renacimiento español. Taurus Ediciones, Madrid, 989, pp. 123-124.

101 Era natural de Gascuna. GONI GAZTAMBIDE, J.: "Los obispos de Pamplona del siglo XIV”, en Príncipe de Viana, n. ${ }^{\circ} 86-87,1962$, pp. 5-194.

102 FERNÁNDEZ LADREDA, C. y LORDA, J.: op. cit., p. 223. Esta hipótesis no es aplicable a la Capilla de Santa Catalina porque no fue concebida como una torre, rasgo presente en la Capilla Barbazana formar parte del recinto amurallado de la ciudad.

103 Así se la denomina en la cita documental más antigua (1378), además de que su ubicación en la panda oriental del claustro y el tratamiento tripartito de su fachada corresponden a este tipo de edificios. FERNÁNDEZ LADREDA, C., LORDA, J.: op. cit., p. 222.

104 FERNÁNDEZ LADRERA, C., LORDA, J.: op. cit., p. 223 
Un último elemento de similitud, que no se suele considerar y al que concedemos cierta relevancia, es la galería calada que, formada por arcos trilobulados, adorna el coronamiento de ambas capillas. Ya hemos señalado anteriormente cómo esta galería se había usado como remate en la fábrica de la catedral de Burgos. Parece lógico deducir que fuera ese el modelo que se tomó para coronar la sala capitular, transfiriéndose después a la capilla Barbazana, donde el uso del arco trilobulado se restringe, por su mayor valor ornamental, a la fachada occidental, mientras que las demás galerías se forman con arcos apuntados. La disposición actual del tejado de la Capilla Barbazana es la misma que presentaba la Capilla de Santa Catalina antes de la restauración del claustro, pero, como sucedía en este caso, tampoco corresponde a su cubierta original, sino a una reforma de finales del siglo XVIII ${ }^{105}$.

Las diferencias entre ambos edificios son, asimismo, evidentes. La estructura de los piso inferiores es completamente distinta, ya que la cripta de la Capilla Barbazana tiene un pilar central en el que apean los nervios y la fachada abierta a la panda oriental del claustro es tripartita, con una puerta flanqueada por ventanas, tipología frecuente en las salas capitulares de los siglos XII y XIII. La capilla propiamente dicha y la cripta se comunican por medio de una escalera de caracol construida en un husillo ubicado en el ángulo suroeste. En la sala capitular de Burgos, en cambio, ambos pisos se concibieron independientes, sin comunicación entre sí, el piso inferior se cubre con bóvedas cuatripartitas y el acceso desde el claustro alto consta únicamente de una puerta, cuyo modelo se encuentra en la propia catedral, en el acceso al claustro desde el brazo sur del crucero.

El elemento arquitectónico más destacado del primitivo coronamiento de la Capilla de Santa Catalina -un pináculo principal de base octogonal flanqueado por otros menores de sección cuadrada- se emplazó en el ángulo sudoccidental. Asimismo, en el remate exterio de la Capilla Barbazaba sobresale por sus dimensiones el pináculo de base octogonal que se alza sobre la torrecilla poligonal del ángulo sudoccidental, en cuyo interior se aloja la escalera de acceso a la cubierta, función que posee particular importancia por el carácter defensivo del edificio, integrado en el recinto amurallado de la ciudad y su paso de ronda ${ }^{106}$ Una torre similar, octogonal con remate piramidal y escalera interior, se utilizó en la sala capitular de Valencia, aunque de proporciones más esbeltas y situada en el punto medio del lado occidental ${ }^{107}$. El pináculo principal de la Capilla Barbazana se acompaña de otros de menores dimensiones y base cuadrada situados sobre contrafuertes y esquinas.

105 GALBETE MARTINICORENA, V:: "La Capilla Barbazana en la Catedral de Pamplona. Una aproxima ción a su traza y evolución", en Revista Príncipe de Viana, n. ${ }^{\circ} 219,2000$, pp. 9-20. 106 Ibid.
El abovedamiento de la Capilla Barbazana se ha atribuido a Juan Torteu o Cortel, mencionado como maestro mayor de la obra de la Catedral de Pamplona en $1342^{108}$. Más recientemente se ha relacionado con el maestro Guillermo Inglés quien, conocedor de los modelos de las salas capitulares de su tierra natal, habría proyectado la bóveda actuando como maestro de obras de la catedral ${ }^{109}$. Asimismo, se ha especulado con el papel desempeñado por el dosel de la Virgen de la Epifanía del claustro de la Catedral de Pamplona como posible modelo previo en miniatura de la bóveda de la Capilla Barbazana ${ }^{110}$. La escultura de la Virgen es obra Jacques Perut y se viene datando hacia 1300, pero la fecha del dosel, que pudo añadirse posteriormente, se desconoce ${ }^{111}$

La tipología de la Capilla Barbazana se repite en la antigua sala capitular de la Catedral de Valencia (1356-1369), promovida por el obispo Vidal de Blanes, pero adaptada al gótico mediterráneo. Su autoría se atribuye a Andreu Juliá, maestro de obras de la Catedral de Valencia entre 1358 y $1381^{112}$.

Lamentablemente, nada sabemos de la autoría del proyecto de la Capilla de Santa Catalina de la Catedral de Burgos ni de los artífices que intervinieron en su edificación. El uso de la vara burgalesa para definir el patrón métrico de la capilla podría estar relacionado con la intervención en su trazado de un maestro local o un maestro foráneo que hubiera asimilado los usos arquitectónicos locales. En este mismo sentido hay que considerar la adopción de soluciones locales tales como las claves de los nervios de embocadura de las

107 Este elemento ha sido relacionado con las torres de remate piramidal situadas sobre la puerta de acceso al palacio papal de Aviñón (ZARAGOZÁ CATALÁN, A., Arquitectura Gótica Valenciana. Siglos XIII-XV, Tomo I, Valencia, 2000, p. 92. ZARAGOZÁ CATALÁN, A., VILA FERRER, S., "La Capilh del Santo Cáliz de la Cena del Señor Antigua Sala Capitular de la Catedral de Valencia", en NAVARRO SORNÍ, M. (coord), Valencia, Ciudad del Grial. El Santo Cáliz de la Catedral. Ayuntamiento de ValenSORN, M. (coord),

108 FERNÁNDEZ-LADREDA, C, y LORDA, J: op cit., p. 220

109 FERNÁNDEZ-LADREDA AGUADÉ, C.: "El gótico navarro en el contexto hispano y europeo", Cuader nos de la Cátedra de Patrimonio y Arte de Navarra, n. ${ }^{3} 3,2008$, pp. 87-125 (p. 96)

110 IBÁÑ̃EZ FERNÁNDEZ, J. y ZARAGOZÁ CATALÁN, A.: "Las microarquitecturas y la generación y transmisión de las formas arquitectónicas en el mundo ibérico entre los siglos XIV y XVI”, en ALONSO RUIZ, B. y RODRÍGUEZ ESTÉVEZ, J. C. (coord.): 1514. Arquitectos góticos en la encrucijada, Univetsidad de Sevilla, 2016, pp, 411-426 (p. 415)

111 ZARAGOZÁ CATALÂN, A., IBÁÑEZ FERNÁNDEZ, J.: "Materiales, técnicas y significados en torno a la arquitectura de la Corona de Aragón en tiempos del Compromiso de Calpe (1410-1412)", Artigrama, n. 26,2011, pp. 21-102 (p. 43 )

112 ZARAGOZÁ CATALÁN, A., VILA FERRER, S.: op. cit. 
bóvedas angulares presentes en la cabecera de la iglesia abacial de Las Huelgas, así como de elementos presentes en la propia catedral, como la configuración de las bóvedas angulares y la galería calada de arquillos del coronamiento.

\section{CONCLUSIONES}

La Capilla de Santa Catalina es un edificio sobresaliente en el panorama arquitectónico castellano de la primera mitad del siglo XIV. Sus contemporáneos eran plenamente conscientes de su singularidad, grandeza y vinculación con la Corona: fue el lugar elegido en 1379 para depositar y honrar el cuerpo de Enrique II en la Catedral de Burgos ${ }^{113}$.

La sala capitular de Burgos anticipa soluciones que poco después adopta la capilla funeraria nobiliaria. La Capilla de San Blas de la Catedral de Toledo, construida para enterramiento del arzobispo don Pedro Tenorio y terminada, en lo que arquitectónicamente se refiere, en 1399, reproduce un espacio cúbico de planta cuadrada, bóveda central ochavada (aunque de nervios radiales) y trompas nervadas en los ángulos a su misma altura. Esta solución difiere de la que se había adoptado anteriormente en la Capilla de San Ildefonso del arzobispo Gil Carrillo de Albornoz, fundada a partir de 1364 en el eje principal de la cabecera del templo, donde el espacio se ochava desde la base en la mitad oriental del edificio y a medio alzado en el lado occidental abierto a la girola. Tanto en la sala capitular burgalesa como en las capillas funerarias de los prelados toledanos subyace un mismo concepto de espacio central, amplio y unitario. La capilla funeraria de promoción episcopal será adoptada como modelo de la capilla nobiliaria en la Capilla de Santiago de la Catedral de Toledo, comenzada a partir de 1430, en la que interviene Hanequin de Bruselas. La capilla de don Álvaro de Luna es de mayores dimensiones que la de San Ildefonso, pero adopta su misma planta y configuración general cubriéndose ahora con una bóveda estrellada de ocho puntas y bóvedas angulares de trirradiales -que ochavan a medio alzado las esquinas del lado de acceso desde la girola- rasgos que comparte con la Capilla de Santa Catalina de la Catedral de Burgos.

113 Desde entonces los capellanes añadieron a la obligación de decir las misas en el altar de Santa Catalina la de salir después al sitio donde estuvo depositado el cuerpo de Enrique II, como consta en el documento de febrero de 1380 (ACB. V-4 1, 212. 24/02/1380), que cita Martínez Sanz (op. cit., p. 142)
En Burgos los modelos de promoción episcopal tardarán más tiempo en transferirse a las grandes promociones nobiliarias. Las principales novedades se han asociado a Juan de Colonia, en un contexto general caracterizado por la llegada a Castilla de artífices de origen nórdico. Las dimensiones y el efecto espacial de conjunto de la Capilla de la Visitación de la Catedral de Burgos, que Juan de Colonia erigió para enterramiento del obispo don Alonso de Cartagena ${ }^{114}$ en el sitio que el Cabildo le concedió en febrero de $1440^{115}$, son modestos en comparación con la monumentalidad de la Capilla de Santa Catalina, si bien las novedades se centraron en el abovedamiento del espacio rectangular, con una rueda octogonal y ligaduras rectas asociada a una estrella de cuatro puntas en el primer $\operatorname{tramo}^{116} \mathrm{y}$ una bóveda sin nervios cruceros en el segundo. En cambio, el espacio central cúbico de la Capilla de Santa Catalina es asimilable al tramo principal de planta cuadrada de la Capilla de la Concepción de la Catedral de Burgos (1477-1483 ${ }^{117}$ ) que Juan de Colonia habría iniciado en 1477 para enterramiento del obispo don Luis de Acuña ${ }^{118}$. Su abovedamiento, atribuido a Simón de Colonia al haber fallecido su padre en $1481^{119}$, en cambio, es muy diferente. La bóveda no es ochavada y tiene forma de estrella de cuatro puntas que, girada, se repite en su centro, además de desarrollar un nuevo sentido ornamental con la incorporación de caireles

114 La atribución al maestro Juan de Colonia de las agujas de las torres y de la Capilla de la Visitación está admitida de forma generalizada, a pesar de que no existir evidencia documental que la respalde. Una visión crítica al respecto en MENÉNDEZ GONZÁLEZ, N.: "Juan de Colonia en los inicios de tardogótico burgalés", en JIMÉNEZ ALCÁZAR, J. F., MAÍZ CHACÓN, J., VILLANUEVA MORTE, C. y CALDERÓN MEDINA, I. (coord.): Actas del IV Simposio Internacional de jóvenes medievalistas, Universidad de Murcia-Ayuntamiento de Lorca, 2009, pp. 145-160.

115 MARTÍNEZ SANZ, M.: op. cit., p. 94. La fecha de finalización de las obras no está tan clara: el mismo autor da noticia de un acta capitular de 6 de abril de 1442 que parece referirse a la Capilla de la Visitación como obra ya hech (ibid. p. 95), pero López Mata dice que el prebado solicitó licencia para tecibich una carta fechada el 3 de enero de 1446 (LÓPEZ MATA, T.: op. cit., pp. 275-276)

116 Después de la sala capitular, el recurso a los terceletes tuvo continuidad en la Catedral de Burgos en la Capilla de Santa Catalina que se abre a la nave sur, modificada a fines del siglo XIV bajo el patronato de la familia de los Rojas, tras ser elegida en 1394 para su enterramiento por doña María de Leiva, esposa de Juan Martínez de Rojas, como dio a conocer Martínez Sanz (op. cit., pp. 269-270). El tramo central de la capilla se cubre con una bóveda estrellada de cuatro puntas, con terceletes y ligaduras al polo central. Un estudio reciente en MATESANZ DEL BARRIO, J: Las capillas de San Juan de Sahagún y de las Reliquias en la Catedral de Burgos. Caja Círculo, Burgos, 2007.

117 LÓPEZ MATA, T.: op. cit., p. 350

118 MARTÍNEZ SANZ, M.: op. cit., p. 128

119 LÓPEZ MATA, T.: op. cit., p. 350 
en las nervaduras, motivo ornamental cuya introducción en Burgos, no obstante, se debería a Juan de Colonia ${ }^{120}$. En la difícil bóveda estrellada del tramo de ingreso se prescindió de los nervios diagonales, como se había hecho antes en la Capilla de la Visitación.

La renovación continúa con Simón de Colonia en la Capilla de la Purificación de la Catedral de Burgos (1482-1494), donde crea un tipo de capilla funeraria que será prototipo de una serie de capillas relacionadas con el linaje Fernández Velasco ${ }^{121}$. Simón de Colonia recurre a la solución - conocida ya en Castilla- de ochavar el espacio central a partir de medio alzado y sustituye las bóvedas angulares nervadas por grandes trompas semicónicas, iniciando el camino por el que discurrirá la arquitectura del Renacimiento, que sustituye definitivamente la bóveda angular nervada por la trompa avenerada ${ }^{122}$. La configuración octogonal de la parte superior de la capilla adquiere una inusitada luminosidad por medio de amplios ventanales. El espacio se complica con la adición de capillas laterales. El dibujo de la bóveda ochavada responde a un esquema en el que se duplica la forma de estrella de ocho puntas sin el concurso de cruceros diagonales, destacando la estrella central por medio del calado parcial de la plementería ${ }^{123}$. La obra de Simón de Colonia es la culminación tardogótica de un concepto espacial y un sistema de abovedamiento de los que la antigua sala capitular de Burgos participa en sus inicios singularmente.

Destaca, asimismo, que la proyección de la Capilla de Santa Catalina como modelo de la arquitectura religiosa se extienda hasta finales del siglo XV, a pesar de las influencias nórdicas que revitalizaron las fórmulas arquitectónicas locales. Para cubrir algunas obras de singular monumentalidad y planta cuadrada se recurre al modelo de la sala capitular

120 GARCÍA CUETOS, M. P.: "En los límites de la sombra como arquetipo historiográfico. La llegada de Juan de Colonia y su aportación a la arquitectura tardogótica en Castilla", en ALONSO RUIZ, B. (coord.): Los últimos arquitectos del Gótico, Grupo de Investigación de Arquitectura Tardogótica, 2010, pp. 71-146.

ALONSO RUIZ, B.: Arquitectura tardogótica en Castilla: los Rasines. Universidad de Cantabria, Santander, 2003, pp. 151-152.

122 GÓMEZ MARTÍNEZ, J.: "El arte de la Montea entre Juan y Simón de Colonia", en YARZA LUACES, J., IBÁÑ̃EZ PÉREZ, A.C. (eds.): Actas del Congreso Internacional sobre Gil de Siloe y la Escultura de su época. Caja de Burgos, Burgos, 2001, pp. 355-366.

123 El esquema de estrella central pudo haber sido utilizado por Juan de Colonia en el cimborrio primitivo de la Catedral de Burgos, si se admite la hipótesis de que el cimborrio edificado en el siglo XVI repite, en gran medida, las formas y estructura de aquel. PAYO HERNANZ, R. J., MATESANZ DEL BARRIO, J.: El cimborrio de la Catedral de Burgos: historia, imagen y símbolo. Real Academia Burgense de Historia y Bellas Artes. Institución Fernán González, Burgos, 2013, p. 25 de la Catedral de Burgos, que se reproduce con sorprendente fidelidad: abovedamiento octogonal en forma de estrella de ocho puntas, bóvedas angulares nervadas en forma de $\mathrm{Y}$, pilares con baquetones ${ }^{124} \mathrm{y}$ ámbito espacial cúbico. La única variación destacable es la reducción del número de claves de diecisiete a trece. Así sucede en la capilla mayor del monasterio de San Salvador de Oña y la capilla mayor de la iglesia de Santo Tomás de Arnedo $^{125}$. Ambos casos representan la adopción de una sala capitular del siglo XIV como referencia para capillas mayores centralizadas de sendos templos de finales del siglo XV, en el caso de Arnedo abarcando la anchura de sus tres naves. Los dos edificios han sido relacionados con Juan de Colonia o su círculo. En el primer caso, si bien el maestro germano pudo intervenir inicialmente en el edificio, quien estuvo al frente de las obras desde 1466 hasta su finalización fue el cantero burgalés Fernando Díaz ${ }^{126}$. La relación del maestro alemán con la capilla mayor de Santo Tomás de Arnedo no está documentada y solamente se sabe que estaba en construcción en 1482 y que, probablemente, estuviera terminada en $1490^{127}$. Lo que parece indudable es que ambas capillas responden a la recuperación del modelo arquitectónico de la Capilla de Santa Catalina de la Catedral de Burgos ${ }^{128}$.

24 Las paredes de la capilla corresponden a una primera fase constructiva iniciada hacia 1332 y la bóved estrellada a la reforma del siglo XV, comenzada en 1465 y concluida hacia 1470. SILVA MAROTO, M. P.: "El monasterio de Oña en tiempo de los Reyes Católicos", Archivo Español de Arte, t. XLVII, n. ${ }^{\circ} 186$, 1974, pp. 109-128. No conocemos las características de la obra del siglo XIV ni las modificaciones que en los paramentos se pudieron introducir en la reforma del siglo XV, pero respecto a la transferencia de los soportes adosados presentes en la Capilla de Santa Catalina un dato significativo es que la capilla del Monasterio de Oña se inicia cuando la construcción de la sala capitular catedralicia se hallaba en un estado avanzado.

125 BARRÓN GARCÍA, A.: op. cit., p. 233. Destaca las evidentes similitudes existentes entre las capillas mayores de Oña y Santo Tomás de Arnedo, de una parte, y la Capilla de Santa Catalina, de otra. Ante la falta de documentación catedralicia del siglo XV, el autor parece sugerir la posibilidad de que el propio Juan de Colonia hubiera intervenido en la sala capitular de la Catedral de Burgos.

26 SILVA MAROTO, M. P.: op. cit. La relación de Fernando Díaz con los Colonia se constata a finales del siglo XV en la capital burgalesa, cuando termina la edificación de la capilla mayor de la iglesia de Monasterio de la Merced que había iniciado Simón de Colonia (POLANCO MELERO, C.: "Nicolás de Vergara y las casas principales de Juan de Lerma, arcediano de Briviesca (1520-1523)", Boletín de la Institución Fernán González, n. ${ }^{\circ}$ 240, 2010/1, pp. 111-129.

127 BARRÓN GARCÍA, A.: op. cit., p. 233.

128 En el caso de la iglesia del monasterio de Oña esta filiación ha sido recordada recientemente (MARTÍN MARTÍNEZ DE SIMÓN, E.: "Las reformas del siglo XV en la iglesia del monasterio de San Salvador de Oña. Estado de la cuestión", en SÁNCHEZ DOMINGO, R. (coord.): Oña. Un milenio. Actas del Congreso Internacional sobre el Monasterio de Oña (1011-2011), 2012, pp. 634-746). 


\section{BIBLIOGRAFÍ}

ABEGG, R.: Königs- und Bischof Monumente. Die Skulpturen des 13. Jahrhunderts im Kreuzgang der Kathedrales von Burgos. Zurich InterPublishers, Zurich, 1999.

ABELLA VILLAR, P.: "El complejo catedralicio burgalés a lo largo de la Edad Media (siglos XI-XIV). Hipótesis para un debate", Porticvm. Revista d'Estudis Medievals, n. ${ }^{\circ}$ III, 2012, pp. 7-34.

ALONSO RUIZ, B.: Arquitectura tardogótica en Castilla: los Rasines. Universidad de Cantabria, Santander, 2003

ÁLVAREZ BORGE, I.: "Nobleza y señoríos en Castilla la Vieja meridional a mediados del siglo XIV”, Brocar. Cuadernos de Investigación Histórica, n. ${ }^{\circ}$ 21, 1998, pp. 55-117.

ARRÚE UGARTE, M. B.: “El sistema ‘hallenkirchen’ en La Rioja: de los modelos conservados al singular ejemplo de San Millán de la Cogolla”, en LACARRA DUCAY, M.C. (coord.): Arquitectura religiosa del siglo XVI en España y Ultramar. Institución Fernando el Católico, Zaragoza, 2004, pp. 115-158.

BANGO, I., BARBÉ-COQUELIN DE LISLE, G., CAAMAÑO, M.: Historia de la arquitectura española. Ed. Planeta, Barcelona, 1985.

BANGO TORVISO, I.: "El espacio para enterramientos privilegiados en la arquitectura medieval española”. Anuario del Departamento de Historia y Teoría del Arte. (U.A.M.). Vol. IV, 1992, pp. 93-312.

BARRÓN GARCÍA, Aurelio A.: "Bóvedas con figuras de estrellas y combados del Tardogótico en La Rioja”, Turiaso XXI, Tarazona 2012-2013, pp. 219-267.

CARRERO SANTAMARÍA, E.: "Restauración monumental y opinión pública. Vicente Lampérez en los claustros de la catedral de Burgos", LOCVS AMCENVS, n. ${ }^{\circ} 3,1997$, pp. 161-176.

CARRERO SANTAMARÍA, E.: "El claustro funerario en el medievo o los requisitos de una arquitectura de uso cementerial”, Liño 12. Revista Anual de Historia del Arte, 2006, pp. $31-44$
CORTÉS ECHANOVE, L.: "De cómo la ciudad de Burgos logró el aislamiento de su Catedral”, Boletín de la Institución Fernán González, n.o 176, 1971, pp. 522-557.

DÍAZ MARTÍN, L. V.: Los orígenes de la Audiencia Real castellana, Secretariado de Publicaciones de la Universidad de Sevilla, 1997.

DIETERICH, B.: Die architekturgeschichtliche Stellung des quadratischen stützenlosen Kapellenraumes im spanischen Skaralbau des XIV. Jhs. Disertación para obtener el doctorado de la Facultad de Filosofía de la Universidad Ludwig Maximilians de Múnich, Madrid, 1973.

FERNÁNDEZ LADREDA, C. y LORDA, J.: "Dependencias claustrales. Capilla Barbazana, refectorio, cocina y dormitorio", en NAVALLAS REBOLÉ, A. (dir.): La Catedral de Pamplona. 1394-1994, Pamplona, 1994, t. I, pp. 219-245.

FERNÁNDEZ-LADREDA AGUADÉ, C.: "El gótico navarro en el contexto hispano y europeo", Cuadernos de la Cátedra de Patrimonio y Arte de Navarra, n. o 3, 2008, pp. 87-125.

FLÓREZ, E.: España Sagrada. Tomo XXVI. Contiene el estado antiguo de las Iglesias de Auca, de Valpuesta y de Burgos. Madrid, 1776.

FRANCO MATA, A.: "Las Capillas", La Catedral Primada de Toledo. Dieciocho siglos de Historia. Diario de Burgos-Promecal, 2010, pp. 180-225.

FRANKL, P.: Arquitectura gótica. Ed. Cátedra, Madrid, 2002.

GAlBete MARTINICORENA, V.: "La Capilla Barbazana en la Catedral de Pamplona. Una aproximación a su traza y evolución”, Revista Príncipe de Viana, n. ${ }^{\circ}$ 219, 2000, pp. 9-20.

GARCÍA CUETOS, M. P.: "En los límites de la sombra como arquetipo historiográfico. La llegada de Juan de Colonia y su aportación a la arquitectura tardogótica en Castilla”, en ALONSO RUIZ, B. (coord..): Los últimos arquitectos del Gótico, Grupo de Investigación de Arquitectura Tardogótica, 2010, pp. 71-146.

GARCÍA ORTEGA, A.J.: "Tipo, tamaño y medida en la arquitectura gótica. El foco burgalés (ss. XIII-XIV)”, EGA. Expresión Gráfica Arquitectónica, Universidad Politécnica de Valencia, n. ${ }^{\circ} 17,2012$, pp. 210-219. https://doi.org/10.4995/ega.2011.929. 
GLERO DE LA FUENTE, C.M.: "Juan Estébanez de Castellanos, canciller de Alfonso XI entre Sahagún y Burgos", en DEL VAL VALDIVIESO, M.I., MARTÍN CEA, J. C. y CARVAJAL DE LA VEGA, D. (eds.): Expresiones del poder en la Edad Media. Homenaje al profesor Juan Antonio Bonachía Hernando, Universidad de Valladolid, Valladolid, 2019, pp. 53-62.

GÓMEZ BÁRCENA, M. J.: Escultura gótica funeraria en Burgos. Excma. Diputación Provincial de Burgos, Burgos, 1988.

GÓMEZ MARTÍNEZ, J.: El gótico español de la Edad Moderna. Bóvedas de crucería. Universidad de Valladolid, Valladolid, 1998

GÓMEZ MARTÍNEZ, J.: "El arte de la Montea entre Juan y Simón de Colonia”, en YARZA LUACES, J., IBÁÑEZ PÉREZ, A.C. (eds.): Actas del Congreso Internacional sobre Gil de Siloe y la Escultura de su época. Caja de Burgos, Burgos, 2001, pp. 355-366.

GONZÁLEZ CRESPO, E.: “Organización de la cancillería castellana en la primera mitad del siglo XIV”, La España Medieval, n. ${ }^{\circ}$ 8, 1986, pp. 447-470.

GOÑI GAZTAMBIDE, J.: "Los obispos de Pamplona del siglo XIV", Príncipe de Viana, n. ${ }^{\circ}$ 86-87, 1962, pp. 5-194.

IBÁÑEZ FERNÁNDEZ, J. y ZARAGOZÁ CATALÁN, A.: "Las microarquitecturas y la generación y transmisión de las formas arquitectónicas en el mundo ibérico entre los siglos XIV y XVI", en ALONSO RUIZ, B. y RODRÍGUEZ ESTÉVEZ, J. C. (coord.): 1514. Arquitectos góticos en la encrucijada, Universidad de Sevilla, 2016, pp. 411-426.

LÓPEZ MATA, T.: La Catedral de Burgos. Hijos de Santiago Rodríguez, Burgos, 1966. Reedición con estudio introductorio de MATASANZ DEL BARRIO, J., Instituto Municipal de Cultura y Turismo, Ayuntamiento de Burgos, Burgos, 2008.

NUEVE RESTAURA S.L.: “Capilla de Santa Catalina, 2016. Informe”.

KARGE, H.: La Catedral de Burgos y la Arquitectura del siglo XIII en Francia y España. Junta de Castilla y León, Consejería de Cultura y Turismo, Valladolid, 1995.

MARÍAS, F.: El largo siglo XVI. Los usos artísticos del Renacimiento español. Taurus Ediciones, Madrid, 1989.
MARTÍN MARTÍNEZ DE SIMÓN, E.: "Las reformas del siglo XV en la iglesia del monasterio de San Salvador de Oña. Estado de la cuestión”, en SÁNCHEZ DOMINGO, R. (coord.): Oña. Un milenio. Actas del Congreso Internacional sobre el Monasterio de Oña (1011-2011), 2012, pp. 634-746.

MARTÍNEZ AÑÍBARRO Y RIVES, M.: Intento de un Diccionario Biográfico y Bibliográfico de autores de la provincia de Burgos. Madrid, imprenta y fundición de Manuel Tello, 1889.

MARTÍNEZ SANZ, M.: Historia del Templo Catedral de Burgos escrita con arreglo a documentos de su Archivo. Imprenta de Don Anselmo Revilla, Burgos, 1866, pp. 138-143 y 296-298. Edición facsímil con estudio, bibliografía e índices de IBÁÑEZ PÉREZ, A.C. y BALLESTEROS CABALLERO, F., Asociación Amigos de la Catedral-Fundación para el apoyo de la Cultura, Burgos, 1997.

MATESANZ DEL BARRIO, J.: Actividad artística en la Catedral de Burgos de 1600 a 1765. Excma. Diputación Provincial de Burgos, Burgos, 2001

MATESANZ DEL BARRIO, J.: Las capillas de San Juan de Sahagún y de las Reliquias en la Catedral de Burgos. Caja Círculo, Burgos, 2007.

MENÉNDEZ GONZÁLEZ, N.: “Juan de Colonia en los inicios del tardogótico burgalés", en JIMÉNEZ ALCÁZAR, J. F., MAÍZ CHACÓN, J., VILLANUEVA MORTE, C. y CALDERÓN MEDINA, I. (coord.): Actas del IV Simposio Internacional de jóvenes medievalistas, Universidad de Murcia-Ayuntamiento de Lorca, 2009, pp. 145-160.

MIQUEL JUAN, M.: “Aviñón, foco artístico para la Valencia del siglo XIV. El papel del obispo Vidal de Blanes”, en COSMEN, M. C., HERRÁEZ ORTEGA, M. V., PELLÓN GÓ MEZ-CALCERRADA, M. (coord.): El intercambio artístico entre los reinos hispanos y las cortes europeas en la Baja Edad Media. Universidad de León, 2009, p. 321-331.

MOXÓ ORTIZ, S.: "Juan Estévanez de Castellanos. Elevación y caída de un consejero regio en la Castilla del siglo XIV", Studia Silensia. Homenaje a Fray Justo Pérez de Urbel, OSB, T.

I. Excma. Diputación Provincial de Burgos-Abadía de Santo Domingo de Silos, Burgos, 1976, pp. 407-422

NICKSON, T.: "La Catedral: su Historia Constructiva", en VV.AA.: La Catedral Primada de Toledo. Dieciocho siglos de Historia. Diario de Burgos-Promecal, 2010, pp. 148-161. 
ORDÁS DÍAZ, P.: “¿Don Gonzalo Osorio de Villalobos o don Gonzalo de Hinojosa? Un episcopado olvidado en León, 1301-1313", e-Spania, 2017 [En línea]. https://doi.org/10.4000/e-spania.26454

PAMPLIEGA PAMPLIEGA, R.: Pontido y otras dependencias de la Catedral de Burgos, Burgos, 2005.

PAYO HERNANZ, R. J.: "La Catedral de Burgos. Un universo de formas a través de ocho siglos de historia”, en PAYO HERNANZ, R. J. (coord.): La Catedral de Burgos. Ocho siglos de historia y arte, Diario de Burgos-Promecal, Burgos, 2008, pp. 81-118.

PAYO HERNANZ, R. J., MATESANZ DEL BARRIO, J.: El cimborrio de la Catedral de Burgos: historia, imagen y símbolo. Real Academia Burgense de Historia y Bellas Artes. Institución Fernán González, Burgos, 2013.

PEÑA PÉREZ, F. J.: “El Alma del Templo. El Cabildo catedralicio”, en PAYO HERNANZ, R J. (coord.): La Catedral de Burgos. Ocho siglos de historia y arte. Diario de Burgos-Promecal, Burgos, 2008, pp. 125-143.

PEREDA LLANERA, F. J.: Documentación de la Catedral de Burgos (1294-1316). Garrido Ediciones, Burgos, 1984

POLANCO MELERO, C.: "Nicolás de Vergara y las casas principales de Juan de Lerma, arcediano de Briviesca (1520-1523)", Boletín de la Institución Fernán González, n. 240 , 2010/1, pp. 111-129.

RABASA DÍAZ, E. (ed.): El manuscrito de cantería de Joseph Gelabert titulado Verdaderas traçes del Art de picapedrer: transcripción, traducción, anotación e ilustración del texto y los trazados. Colegio Oficial de Arquitectos de las Islas Baleares-Fundación Juanelo Turriano, Madrid, 2011, p. 392. https://issuu.com/juaneloturriano/docs/gelabert_completo_reducido (consultado el 4/09/2020).

RICO, M.: La Catedral de Burgos. Patrimonio del mundo. Burgos, 1985.

RUIZ, T. F.: "Mercaderes castellanos en Inglaterra", en RUIZ, T. F.: Sociedad y poder real en Castilla (Burgos en la Baja Edad Media). Ed. Ariel, Barcelona, 1981, pp.199-224.
SÁNCHEZ AMEIJEIRAS, R.: "History and Stories of Love and Conversion in Fourteenth-Century Burgos", Hispanic research journal, Vol. 13, n. ${ }^{\circ}$ 5, octubre 2012, pp. 449-467.

SERRANO FATIGATI, E.: "Rápida ojeada á la escultura castellana de diversas épocas", Boletín de la Sociedad Española de Excursiones, Año XVI (1918), tercer trimestre, pp. 227-230.

SILVA MAROTO, M. P.: "El monasterio de Oña en tiempo de los Reyes Católicos", en Ar chivo Español de Arte, t. XLVII, n. ${ }^{\circ} 186,1974$, pp. 109-128.

TORRES BALBÁS, L.: Arquitectura gótica. Ars Hispaniae, vol. VII. Editorial Plus Ultra, Madrid, 1952

VALDALISO CASANOVA, C.: "Estévanez de Castellanos, Juan”, Diccionario Biográfico Español (DB-e), Real Academia de la Historia. http://dbe.rah.es/biografias/60265/juan-estevanez-de-castellanos; (consultado el 14/04/2019).

WILSON, Ch.: The Gothic Cathedral. The Architecture of the Great Church, 1130-1530. Thames and Hudson, London, 1990.

YARZA LUACES, J.: Baja Edad Media. Los siglos del gótico. Editorial Sílex, Madrid, 1992.

ZARAGOZÁ CATALÁN, A.: Arquitectura Gótica Valenciana. Siglos XIII-XV, Tomo I. Valencia, 2000.

ZARAGOZÁ CATALÁN, A., IBÁÑEZ FERNÁNDEZ, J.: "Materiales, técnicas y significados en torno a la arquitectura de la Corona de Aragón en tiempos del Compromiso de Calpe (1410-1412)", Artigrama, n. ${ }^{\circ} 26,2011$, pp. 21-102

ZARAGOZÁ CATALÁN, A., VILA FERRER, S.: "La Capilla del Santo Cáliz de la Cena del Señor. Antigua Sala Capitular de la Catedral de Valencia”, en NAVARRO SORNÍ, M. (coord.): Valencia, Ciudad del Grial. El Santo Cáliz de la Catedral. Ayuntamiento de Valencia, Valencia, 2014, pp. 79-105.

ZARAGOZA PASCUAL, E.: "Hinojosa (o Finojosa), Gonzalo", DB-e, Diccionario Biográfico Español de la Real Academia de la Historia. http://dbe.rah.es/biografias/50606/gonzalo-de-hinojosa (consultado el 22/03/2019) 